\title{
Iterative Design of Impact-Damping Gloves for Safer Boxing
}

\author{
Paul Perkins' ${ }^{1,2}$, Alex Jamieson1, Geordie Ferguson ${ }^{3}$, Wayne Spratford ${ }^{1}$, Allan Hahnn ${ }^{1,4,5}$ \\ ${ }^{1}$ University of Canberra, Australian Capital Territory, Australia \\ ${ }^{2}$ Boxing Australia Limited, Canberra, Australia \\ ${ }^{3}$ Stellen Studio, Canberra, Australia \\ ${ }^{4}$ Queensland Academy of Sport, Brisbane, Australia \\ ${ }^{5}$ Griffith University, Brisbane, Australia \\ Email: paul.perkins@boxing.org.au
}

How to cite this paper: Perkins, P., Jamieson, A., Ferguson, G., Spratford, W. and Hahn, A. (2018) Iterative Design of Impact-Damping Gloves for Safer Boxing. Open Journal of Safety Science and Technology, 8, 49-97.

https://doi.org/10.4236/ojsst.2018.83005

Received: June 8, 2018

Accepted: July 29, 2018

Published: August 1, 2018

Copyright $\odot 2018$ by authors and Scientific Research Publishing Inc. This work is licensed under the Creative Commons Attribution International License (CC BY 4.0).

http://creativecommons.org/licenses/by/4.0/

c) (i) Open Access

\begin{abstract}
Design methods were employed over a 5-year period to develop boxing gloves capable of substantially buffering impact forces delivered to an opponent, thereby permitting safer boxing. Multiple concepts were explored, with sophistication of prototypes gradually increasing. The protypes underwent both quantitative laboratory testing and qualitative evaluation in the field. The laboratory testing methods were evolved over time to enhance test reliability and ecological validity. Feedback from the laboratory and field trials was highly instrumental in guiding the process of glove development. It was eventually found that, compared to standard boxing gloves, pneumatic gloves with sealed bladders were effective in reducing peak impact forces and peak rates of force development when impact magnitudes were low to moderate but not when they were high. By contrast, pneumatic gloves incorporating a bladder enabling air exchange with the external environment were protective across the entire range of impact magnitudes likely to be encountered in boxing. These gloves are configured differently from standard gloves in terms of the positioning of the fist relative to the glove padding, but now have close visual resemblance to standard gloves. The aesthetics of the gloves have proven critical to their acceptance. Wearer comfort is also vital and, although we extensively pursued the concept of thumbless gloves, we finally deemed it necessary to include separate thumb compartments to accommodate user advice. There is scope for further glove refinement, but recent experience indicates that the latest version is currently sufficient for use in modified boxing programs that emphasise safety, with such targeted contextual sufficiency realising a fundamental aim commonly associated with projects employing the design approach. Small batches of the gloves have recently been manufactured to cater for modified boxing programs.
\end{abstract}




\section{Keywords}

Boxing Safety, Modified Boxing, Pneumatic Boxing Gloves, Protective Equipment for Boxing, Sport Design

\section{Introduction}

Boxing has a presence in almost every nation throughout the world [1]. It has been included in all but one Summer Olympic Games since 1904, but has been subject to criticism on medical, ethical, legal and sociological grounds [2]. In 2003, a paper published in the British Columbia Medical Journal included the following:

"In boxing, the ultimate achievement is to knock somebody out. And to knock somebody out is to injure his or her brain ... Every year we read of some poor boxer who collapses and dies after a boxing bout as a result of repeated blows to the head. Moreover, we know ... that blows to the head have a cumulative and devastating effect. Twenty years on and the commonly referred to condition of being punch drunk (is) all too easy to recognise ... slurred speech, unsteady legs, lapses of memory, violent tendencies and the general appearance of having had a few too many" [3].

A decade later, the eminent neurologist and geneticist John Hardy expressed the view that:

"Boxing is a special case. No other sport has the express goal of causing injury to the brain. That is certainly the aim of professional boxing. Even in amateur boxing blows to the head are crucial ... No doubt I will be called a killjoy for espousing the view that boxing should be banned ... I would return the charge: nothing can be more killing of joy than personality changes, violence, substance abuse and dementia” [4].

Such views cannot be lightly dismissed. Between 1890 and 2007, there was an average of more than 10 deaths per year from acute injuries received in boxing, with amateur boxers accounting for almost a quarter of these [5]. Several studies have demonstrated structural pathology in the brains of boxers, including changes resembling those associated with Alzheimer's disease [6]-[12]. Biochemical indicators of neuronal damage have been detected in amateur boxers but not age-matched controls [13] [14]. Boxers also show a relatively high incidence of electro-encephalographic (EEG) abnormalities and deficits in cognitive function [15] [16] [17] [18]. Boxing-related injuries were responsible for a total of 437 British Army medical unit admissions from 1969 to 1980 [19]. Head trauma accounted for $\sim 68 \%$ of these, but there were 20 admissions for trunk injuries including rib and vertebral fractures, and 13 for kidney and pelvic organ injuries that required an average hospitalization time of 6.2 days. Between 1990 and 2008, there were 165,602 presentations to United States Emergency Departments for injuries sustained in boxing, with more than 37,000 of these relat- 
ing to head or neck injuries [20].

Legal experts have argued that boxing consists of activities that in other contexts would constitute criminal assault and have raised issues relating to the legitimacy of participant consent [21] [22] [23]. Sociologists have claimed that boxing has negative effects by overtly glamorising and rewarding violent conduct [24] and is exploitative of vulnerable young people [25] [26].

There is potential to address objections to boxing through modifications to the rules and equipment. Common suggestions include removal of the head and neck from the target area [21] [27] [28] and the development of gloves capable of substantially reducing impact forces delivered to an opponent [28]. Considerable doubts have been expressed as to whether the boxing community would ever be amenable to such changes [3], since it is believed that the visual, emotional and cultural appeal of the sport to that community is largely tied to its inherent risks [29]. This belief is partially supported by the fact that since the 1890s, there have been more than 20 patents lodged for gloves aimed at markedly decreasing impact forces, but none has led to widespread or sustained adoption of a new glove design [30].

Nevertheless, a few modified boxing programs emphasising participant safety have recently emerged in Australia [31] and elsewhere [32]. After many years of coaching conventional amateur boxing, the first author of this paper spent five years running a modified boxing program at a Police Community Youth Club (PCYC) in Canberra. A survey of long-term participants in that program revealed that they placed high value on safety [33]. This stimulated subsequent efforts to progressively incorporate various safety procedures, including design, development and deployment of impact-damping gloves. The intent was to produce gloves that would not only reduce injury risks but would also be attractive to users in the modified boxing setting and augment the appeal of the modified boxing concept. Although we entertained a vague hope that our work might eventually provide impetus for exploration of similar ideas in the conventional boxing context, our focus was entirely directed toward creating gloves that would be enthusiastically taken up in the modified boxing situation. The purpose of this paper is to outline the progress made.

\section{Overview of Approach}

The project was pursued through an iterative design process incorporating a series of quantitative scientific experiments and the use of various techniques to obtain qualitative feedback. Approval was provided by the Human Research Ethics Committee of the University of Canberra.

Available literature indicates that the design process begins with identification of a practical problem [34] and entails use of solution-focused cognitive strategies derived from abductive and/or appositional thinking [35]. Although deductive and inductive methods typical of the natural sciences may play important roles in the quest for a solution [36], particularly in validation of a designed ar- 
tefact and evaluation of its field performance [34], they are not the fundamental elements of the design process, since the latter is directed primarily toward creation of value rather than determination of facts [36]. Creation of value can consist in finding a satisfactory solution to the problem rather than necessitating achievement of an optimal solution [37]. Unbiased consideration of multiple possible solutions is seen as vital, although questions have been raised concerning the extent to which this typically occurs [38], and it has been proposed that in practice design is often somewhat conjectural, with initial rapid conjecture on what is likely to work guiding subsequent design requirements and constraints [39]. It has been argued that the core challenge of design is the parallel development of an artefact and its way of working [36], as opposed to use of a sequential or linear approach. Cross [40] suggests that in design the relationship between problem and solution is "commutative", implying that the order in which they are addressed need not be fixed. Hatchuel [41] notes that the design process incorporates a concept of "expandable rationality" since the very act of pursuing a solution to a problem can lead to conceptual expansions. He sees social interaction as a critical component of design.

There is debate as to whether design is a specialised branch of science or a distinct epistemological entity. It has been argued that while science is primarily hypothesis driven, the design process is outcome-driven [42] [43]. Science can be seen as focused on a search for universal truths, whereas design is directed toward context-specific invention and often has aesthetic components [44]. Cross [40] contends that method is vital to science but not to design, since design outcomes are intended to be situation-specific, not universally repeatable.

Mahdjoubi [42] questions the popular belief that most innovation stems from scientific research and argues that, historically, non-linear design approaches initiated by a desire to create effective solutions to real-world practical problems have been a prolific source of innovation across numerous fields. He further contends that while science can be useful in guiding the design process, there are also cases in which design approaches provide a stimulus for scientific endeavour [42].

We started this project with a clear goal in mind. We investigated several glove designs that we believed might enable attainment of that goal, and gradually honed our thinking. Our ability to build upon prior designs for impact-damping gloves was limited by a dearth of information on their practical effectiveness. Only one of those designs has undergone published scientific assessment [45]. Since we were also quite restricted in terms of the financial and other resources available for glove development, we operated with a high degree of self-sufficiency in attempting to develop a solution that would meet the specific needs of our modified boxing initiative.

Critical elements of our journey are described below. Since illustration is considered a central element of the language of design [44], substantial use is made of photographs and other graphical representations. 


\subsection{Initial Attempt to Reproduce Pneumatic Gloves}

The one scientifically assessed glove aimed at impact damping was produced by a Finnish physician, Lyderik Löfgren, more than 60 years ago [45]. Like many earlier designs, it incorporated an air-filled bladder in place of standard glove padding. Laboratory testing showed that, compared to conventional gloves, it substantially reduced acceleration of a struck mass attached to a pendulum. An effort to reproduce that glove seemed a logical starting point for our work, although inability to locate relevant drawings made it a challenging task. After discussion with engineers from RMIT University (Melbourne), we initially engaged an external consultant to manufacture a few pairs of pneumatic gloves with characteristics resembling those described by the original inventor. The external consultant was an enthusiastic modified boxing participant with a strong background in technological innovation. He approached the glove development with zeal and during the second half of 2013 produced some early prototype gloves that contained open-cell foam in place of standard glove padding. The surfaces of the foam were coated with rubber. There was a valve that allowed air to be pumped into or extracted from the foam structure to adjust its internal air pressure. As an additional feature evidently not included in the original pneumatic gloves, a small hole was made in the rubber coating to permit air release from the foam structure upon impact, in keeping with a concept patented by Carrillo [46]. The form of the pneumatic gloves was quite similar to that of standard gloves (Figure 1).

Within three months of commencement of the project, the air-containing foam was tested against standard glove padding at the laboratories of Swinburne University of Technology in Melbourne. The testing consisted of dropping samples of the different materials from selected heights on to a Kistler load cell that measured the impact profiles. Additionally, an INSTRON system was used to enable impact force measurements when the different samples were accelerated to known velocity over a set distance. The air-filled foam was tested both with the air hole open and occluded. The experimental set-up is shown in Figure 2.

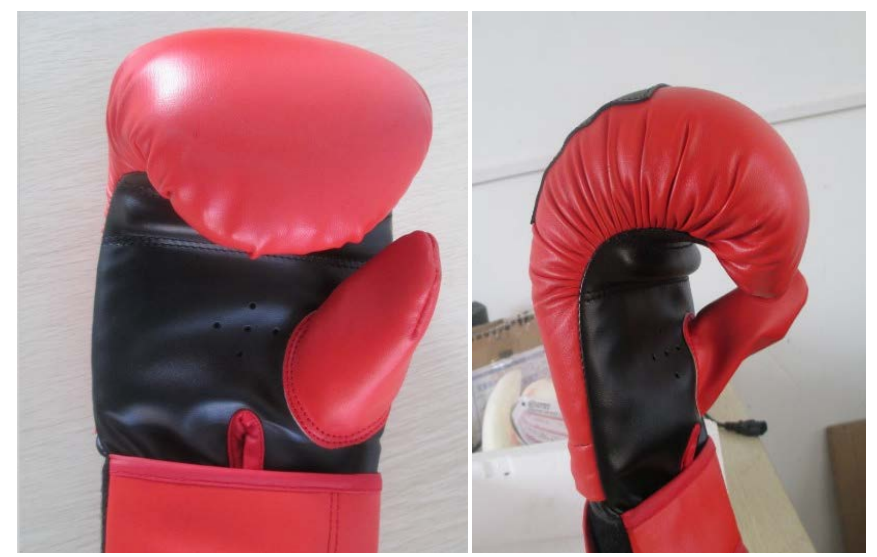

Figure 1. Front and side views of early prototype pneumatic gloves designed to resemble those produced six decades ago in Finland. 


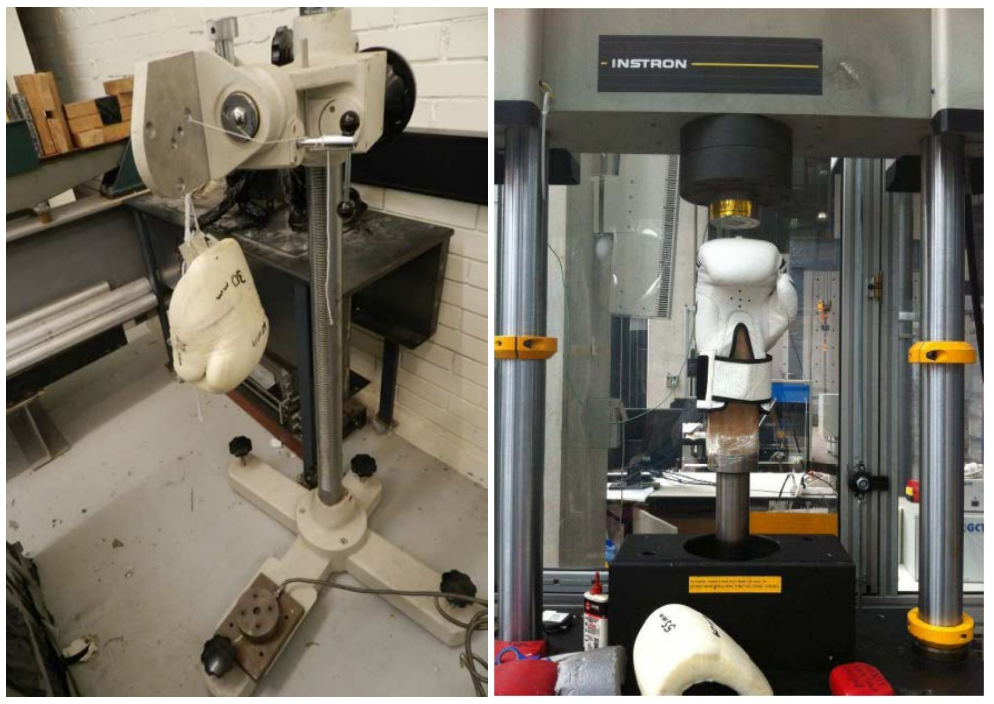

Figure 2. Equipment set-up for drop-weight and INSTRON testing of prototype gloves and air-filled foam materials.

The drop-weight and INSTRON tests produced highly repeatable results for any particular material. The prototype foam structure was softer than standard glove padding. The peak impact force produced when it was attached to a mass of $2.076 \mathrm{~kg}$ and dropped from a height of 0.7 metres on to a load cell was lower than that measured when the same procedure was applied to the standard padding and to a standard intact boxing glove. The situation was reversed, however, when the drop-weight test was performed from a starting height of 1.1 metres, presumably because the prototype material became quite hard once its maximum deformation had occurred. Similar findings were obtained from the INSTRON testing, which indicated that the prototype material offered a protective effect only up to a peak impact force of $\sim 500$ Newtons $(\mathrm{N})$, beyond which point the standard glove padding performed better. The air hole that had been included in the prototype structure had almost no effect in reducing the peak impact force, since the time to peak force was too short for any substantial air release to occur.

Despite these initially disappointing findings, it was recognized that it should be possible to 'tune' the shape of the force curve and reduce the peak value by changing the air pressure inside the prototype structure and either increasing the size of the air release hole or incorporating a series of holes. Some doubt arose however, as to whether enough tuning could occur to provide protective effects up to the very much higher peak forces-perhaps as high as $8000 \mathrm{~N} \mathrm{[47]} \mathrm{—} \mathrm{that}$ reportedly can be generated by boxers.

A new version of the prototype foam structure was produced and an Australian company that manufactures standard boxing gloves was commissioned to supply glove covers specially designed to contain it, but when the covers were delivered the compartment for insertion of the structure was found to be too small. Following this further setback, the external consultant advised that he could not deliver the intended outcome of the project within the available budget and therefore had no choice but to discontinue his involvement. 


\subsection{Alteration of Fist Position Relative to Glove Padding}

With the endeavour to produce effective pneumatic gloves at least temporarily on hold, focus was directed to another idea that had arisen during initial discussion as to how impact buffering might be achieved. This idea concerned the possibility of reducing peak impact forces through alteration of the positioning of the fist relative to the main section of glove padding. We initially conducted some informal trials amongst ourselves by sparring with standard boxing gloves but employing a novel fist position within the gloves. Based on our subjective impressions of the effect, a decision was made to further explore the concept. With assistance from the Brisbane-based company HART Sport Pty Ltd., prototype gloves were produced that required the whole closed fist to be placed into the compartment beyond which the fingers would usually extend (in contrast to the normal process of placing an open hand into the glove and then closing the fist). The portion of the glove that would otherwise contain the fingers was therefore left free, increasing both the thickness of padding in front of the knuckles and the scope for that padding to flex upon impact.

The new gloves were manufactured in vibrant red and blue colors to maximise their visual appeal. After informal tests in training settings, they were used in a 7-bout modified boxing event held at the Canberra PCYC in March 2014 (Figure 3).

All but one of the contestants subsequently completed an anonymous on-line survey. There was unanimous agreement that the gloves reduced impact forces compared with standard gloves. Four athletes indicated that the degree of impact buffering was substantial, eight considered it moderate, and one thought it slight. Four athletes said that they did not enjoy using the prototype gloves, whereas three greatly enjoyed the experience. The remaining six athletes were neutral. Four athletes were either satisfied or very satisfied with the comfort of the gloves, five were neutral, three were unsatisfied and one was very unsatisfied.

In consideration of the formal feedback, and of casual comments subsequently

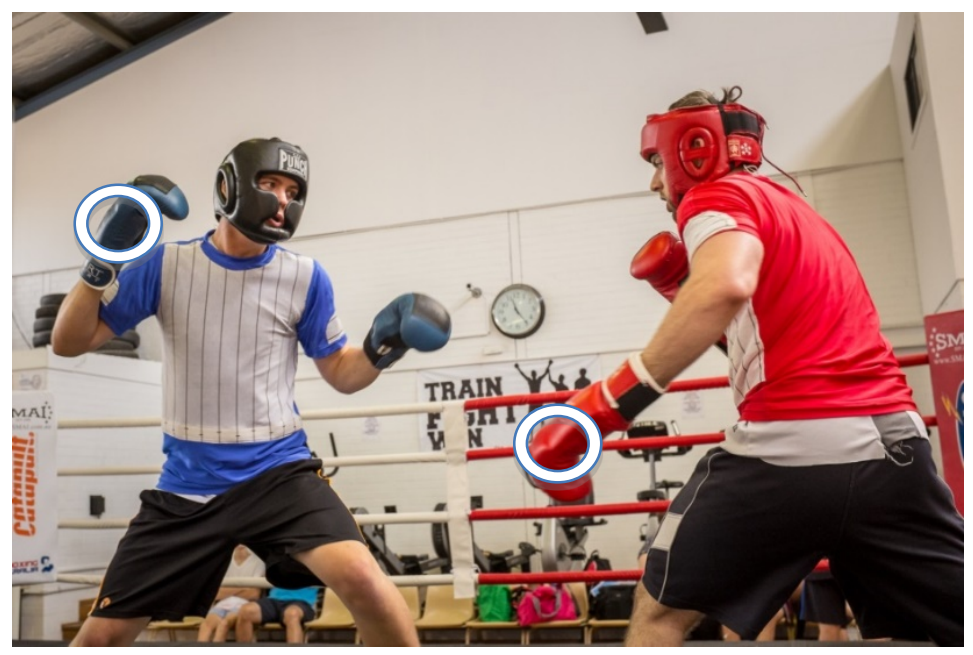

Figure 3. Modified boxing contest with gloves incorporating altered relationship between fist position and padding. Fist was contained in area of glove shown by white circles. 
made by the trial participants, we perceived that we were still far from realizing our over-riding project goal.

\section{Highly Deformable Gloves}

We noted the ability of air-containing party balloons to buffer impact forces as a result of their high elasticity and deformability and imagined that there might be potential to develop boxing gloves embodying these characteristics. It seemed possible that a balloon-like structure contained in a compartment much more elastic than standard glove leather or vinyl could form the "padding" of the glove, with the whole fist positioned behind it in a manner consistent with that tried in the above HART Sport gloves.

With the emergence of this concept, the project moved into a new phase in which we began constructing prototype gloves ourselves rather than arranging for established manufacturers to implement designs. As a first step, we evaluated several different air bladders with a view to finding one that was reasonably balloon-like but resistant to bursting when exposed to high impact forces.

On advice from HART Sport, we eventually selected a Size 1 latex soccer ball bladder manufactured by Enkay [India]. We then cut off the end-section (i.e. the finger section) of a standard training glove and replaced it with a sewn-on, stretchable lycra bag with a sealable opening for insertion of the bladder, which could then be inflated.

A second lycra bag could subsequently be pulled over the whole complex to confer stability and shape and to enclose the thumb, effectively making the glove thumbless as has been recommended by medical authorities [48] [49]. The construction process is illustrated in Figure 4.
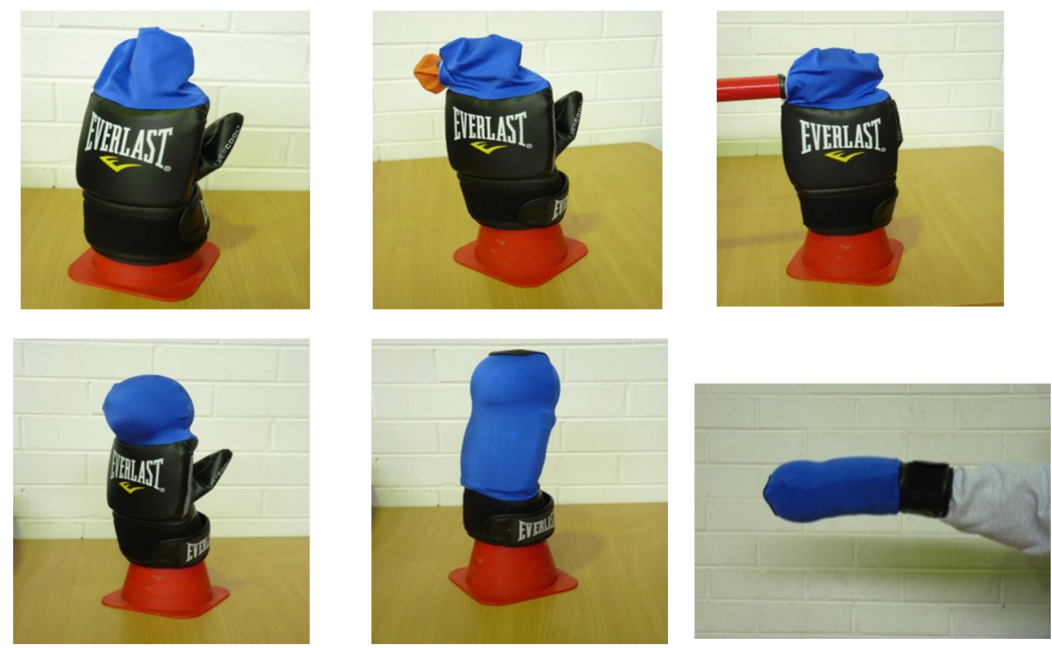

Figure 4. Construction of highly deformable prototype gloves. The end-section of a standard training glove was cut off and replaced by a sewn-on, stretchable lycra bag with a sealable opening for insertion of a small spherical bladder, which could then be inflated. A second lycra bag could subsequently be pulled over the whole complex to provide shape and stability and to enclose the thumb. A glove with fist in position behind the bladder is shown on the bottom right. 
In initial play amongst ourselves, the new gloves seemed subjectively to be have greater impact-buffering capacity than our previous prototypes. We produced multiple pairs in red and blue colors, and in April 2014 they were used at modified boxing (Box' Tag) [31] events in Sydney and Melbourne, with the Melbourne event being part of the Australasian Police \& Emergency Services Games. There were mixed reactions from the contestants. Negative comments on the "look" and "feel" of the gloves were common. On the other hand, all 22 of the Sydney competitors and 11 of 14 Melbourne competitors perceived that the gloves reduced impact forces, with the majority rating the reduction as large. There were some reports that, when impacts were forceful, the bladders could occasionally 'turn under', causing impact to be made with only slightly padded knuckles. In later investigation of possible reasons for these reports, it became clear that inappropriate positioning of the hand within the glove (particularly through extension of the fingers) could lead to the bladder being pulled downward into a position entailing a risk that it would not be the first point of contact with the opponent. To overcome this problem, we subsequently produced "inner" gloves that prevented finger extension.

During the ensuing months, the gloves were occasionally used for sparring sessions held as part of the modified boxing program at the Canberra PCYC. Some positive responses were received, particularly from junior and female athletes and the parents or guardians of program participants, but the athletes never actively sought employment of the gloves and it was evident that, overall, a preference for standard gloves remained.

In December 2014, the prototype low-impact gloves were employed for a modified boxing competition that formed part of a Draft Camp held at the Australian Institute of Sport (AIS) in Canberra for athletes interested in transferring into conventional boxing from other sports. Each of seven athletes interviewed after the competition thought that the gloves were either extremely effective or quite effective in reducing impact forces. Particularly salient were the following comments from two experienced boxing coaches who were present at the event:

Coach 1: "The gloves helped in achieving tonight's intended purpose. It was possible to assess the movement abilities of the athletes without exposing them to significant risk. To evaluate the potential of the athletes for boxing, it will still be necessary to see how they react to taking a solid punch, but tonight the gloves were central to a useful game. I think that when the big boys were involved and there were some power punches, the bladders sometimes bent under allowing the knuckles to make contact, so there are perhaps some design issues that need further attention. For kids, though, the gloves already could be great in allowing safer learning of boxing skills."

Coach 2: "I had some initial reservations about using the gloves as I thought it would be better to see how the athletes respond to being hit. However, I now think the gloves worked very well with the game the athletes played. I don't think the gloves are appropriate for established boxers but they could be used for 
beginners, especially kids."

These comments were interpreted as suggesting that, although ongoing work was required, we were tracking quite well toward the development of gloves that could be suitable for a modified, low-risk form of boxing.

Examination of the gloves after the AIS Draft Camp revealed that some had been damaged, presumably due to the occurrence of harder punching than that typically associated with modified boxing. The most common form of damage was tearing of the lycra bag sewn on to the glove, but stitching was also broken on a few outer bags. In one case, stitching was torn away across virtually the whole area of attachment of the inner lycra bag to the glove under-surface, meaning that the lycra bag was no longer performing its intended function of stabilisation and bladder positioning. It seemed probable that when bladders were greatly compressed, the ability of the lycra to stretch to accommodate lateral expansion was exceeded. This implied a necessity to either search for lycra or other material with more elasticity or impose some structural limit on the scope of lateral bladder compression, even though the latter solution would presumably also reduce the magnitude of impact force buffering.

\section{Refinement of Highly Deformable Gloves}

At the beginning of 2015, we gave considerable further thought to possible reasons for reports that buffering of impacts by the prototype gloves combining the bladders and lycra covers occasionally seemed to fail. Displacement of the spherical bladder from its intended position was recognized as one likely cause of the problem. It was also apparent that even when the bladder was in position, hooked punches (as opposed to straight punches) could sometimes result in the opponent being contacted by the back of the glove in the area behind the bladder, meaning that protection afforded by the bladder would not occur.

We therefore implemented several changes to the gloves. We covered the area behind the bladder with a $2.5 \mathrm{~cm}$ thick layer of medium-density open cell foam. The top of this layer extended to half-way up the bladder and had two arms that extended forward to provide a circular 'cradle' for bladder support. The upper edge of the foam was cut to a shape that enabled efficient seating of the bladder. The changes had the disadvantage of adding to the bulk of the gloves (Figure 5) but were perceived as addressing important deficiencies of the prior prototype. In April 2015, two of us and a colleague with a background in kick-boxing took part in a trial in which each person used the new prototype gloves, conventional $12 \mathrm{oz}$ (Std 12oz) gloves of the type used in competition by amateur boxers in the heavier weight divisions [51], and conventional 16oz (Std 16oz) gloves such as those commonly used by boxers in sparring [52] to deliver a series of subjectively light, medium and heavy impacts to a commercially available apparatus designed and built by the Institut Für Angewandte Trainingswissenschaft [Institute of Applied Training Science] in Leipzig, Germany, specifically for measuring punch characteristics. This apparatus, located at the AIS in Canberra, consisted 
of a wall-mounted force plate covered by a pad with a thickness of $290 \mathrm{~mm}$ including a leather covering, multiple foam layers, two layers of plywood board and a $20 \mathrm{~mm}$ thick aluminium plate to which the load cell was attached. The pad had a frontal surface of $330 \mathrm{~mm}$ square and at the point of maximum width it was $460 \mathrm{~mm}$ square. The aluminium plate at the back of the pad was $350 \mathrm{~mm}$ square. The apparatus, which is shown in Figure 6, incorporated a two-beam laser system that enabled measurement of pre-impact glove velocities. The beams were positioned $44 \mathrm{~mm}$ apart and very close to the target area of the pad.

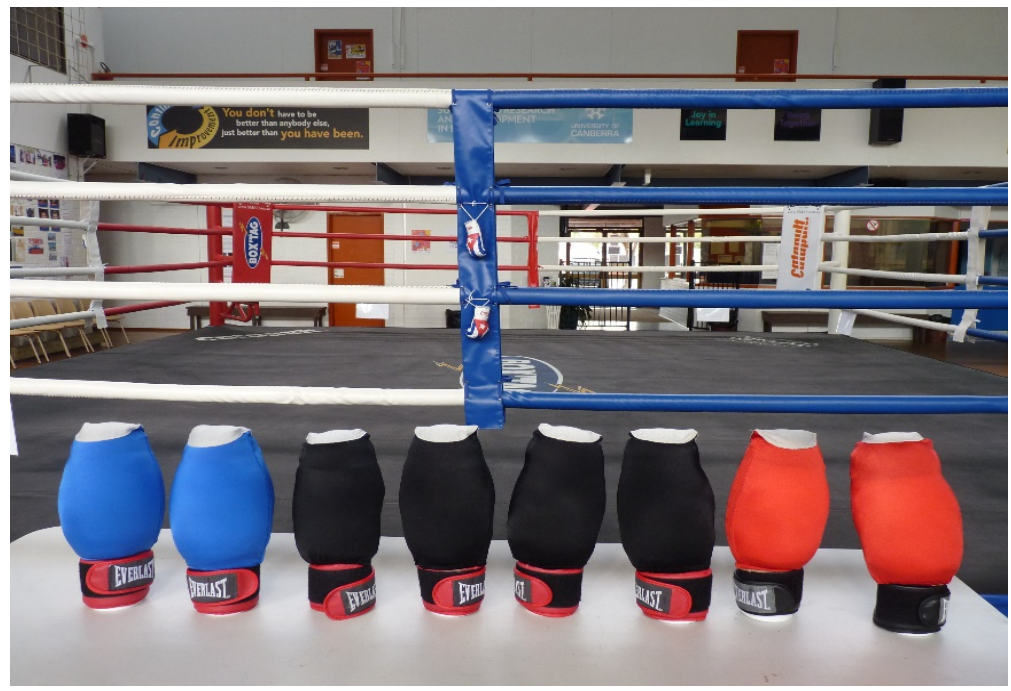

Figure 5. Prototype low-impact gloves with additional foam added to perimeter of glove to increase protection against impacts delivered with a part of the glove other than the bladder. The white areas at the top of the gloves are electrically conductive patches that formed part of automated scoring technology used in Box' Tag [50].

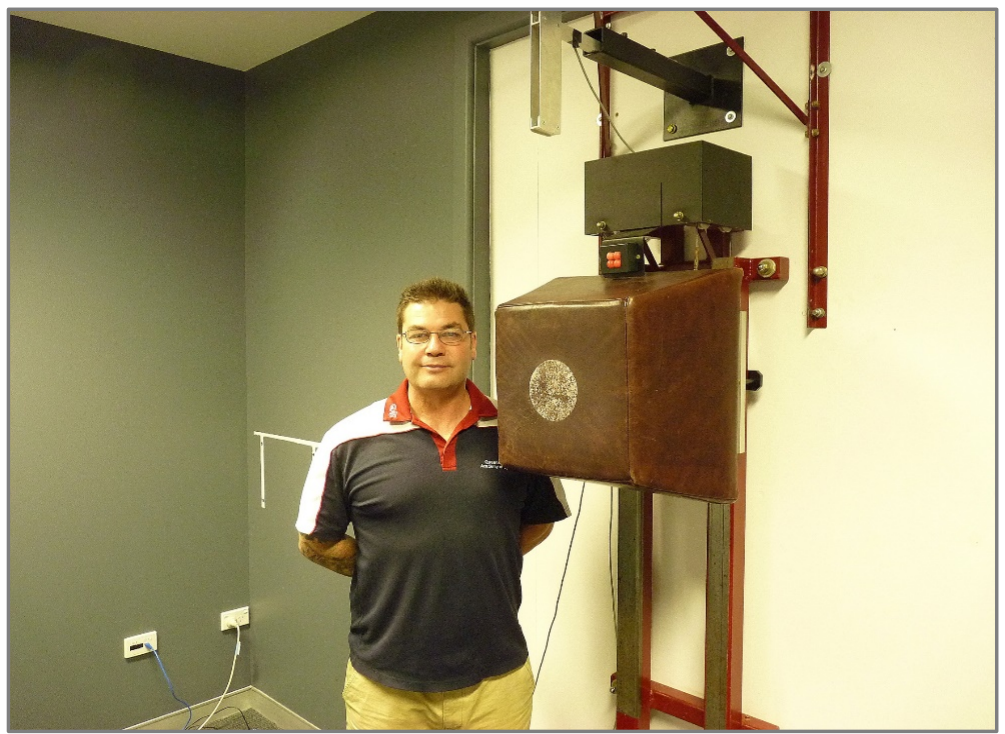

Figure 6. Apparatus at the Australian Institute of Sport, Canberra, for measuring punch characteristics. 
To enable data for the three individuals to be included in a single analysis despite individual differences in the levels of force that could be generated, each peak force reading was converted to a percentage of the personal highest peak force reading recorded on the day, and the same procedure was adopted for pre-impact glove velocities. A plot of percentage force against percentage velocity (Figure 7) suggested that the prototype gloves yielded substantial impact buffering effects across almost all the observed glove velocity range. It was also true, however, that very high glove velocities were seldom attained when the prototype gloves were used. This may be explained partly by the fact that the prototype gloves were $\sim 4-5 \mathrm{~cm}$ longer than the standard gloves, meaning they would have tended to travel over less distance before contacting the target. The decrease in distance could be expected to limit the time available for glove acceleration, hence lowering the velocity eventually reached. It is also possible, though, that some aspect of the form or comfort of the gloves caused the subjects to be slightly more tentative.

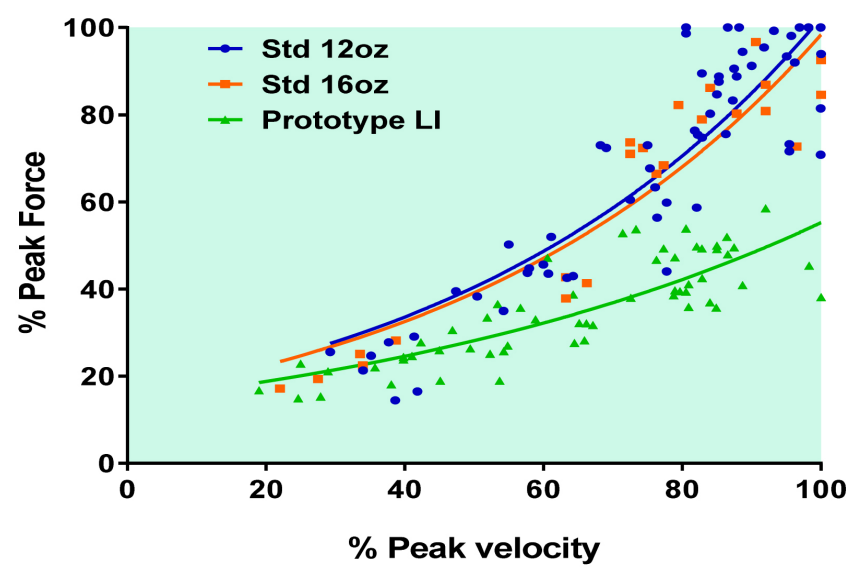

Figure 7. Comparison of performance of the prototype low-impact glove (Prototype LI) against that of conventional $12 \mathrm{oz}$ and $16 \mathrm{oz}$ gloves in initial "punch integrator" tests.

Although the test results were encouraging, the aesthetics of the gloves remained unsatisfying. We attributed this partly to the makeshift and rudimentary nature of our manufacturing process (e.g. the use of kitchen scissors and scalpels to cut foam to required shapes). We took the gloves to a modified boxing event in Sydney, where they were used in two bouts between junior males. In that context, they looked unacceptably large. During the remainder of the event, we showed the gloves to numerous attendees. Although there was interest in what we were trying to achieve, the appearance of the gloves drew broad criticism, and one adult female participant in the Sydney program commented that regardless of the impact-buffering capabilities of the gloves, she "would not be seen dead wearing them". It was evident that further thought concerning glove design was necessary.

\section{A Breakthrough: Building of Gloves around Bladders}

Shortly after the laboratory testing at the AIS it was decided that, instead of us- 
ing commercially available training gloves as a base and adapting them to enable accommodation of a bladder, we should focus on the bladder as the core element of our approach and work out how best to build a glove around it. In retrospect, this decision constituted a major advance in the project. It reduced material costs as the need to purchase training gloves was eliminated, and it also removed constraints as to how various glove components could be arranged as part of the assembly process.

Initially, cardboard cut-outs of a glove "frame" were produced to enable experimentation that culminated in determination of optimal shape and dimensions. Once the characteristics of the frame had been finalized, a cut-out consisting of $0.5 \mathrm{~mm}$ thick rubber was made. Velcro "hook" material was then sewn on to the bottom section of the frame. To one side of it, a strip of elastic was sewn. To the other, a section of Velcro "loop" material covered with grey ripcord fabric was attached. The frame was then flipped over and a rectangular section of $2 \mathrm{~cm}$ thick open cell foam was glued to most of its surface. A triangular strip of the same open cell foam was glued to the rubber and the upper surface of the rectangular strip. The outer ends of the rubber frame were then brought together to create a circular, slanted cradle for the bladder. A notch was cut in the frame to provide access to the bladder valve. After placement and inflation of the bladder, a lycra bag was pulled over the whole unit. The elastic and Velcro materials formed a secure wrist strap (Figure 8).

The glove made in this way had all the features of the previous prototype but its outer surface was smooth and it was much shorter and sleeker. It elicited a positive reaction from participants in the modified boxing program at the Canberra PCYC and, with help from an Industrial Design student from the University of Canberra, a few minor improvements were made in response to their feedback. The impact-buffering effects of the glove were subjectively perceived as substantial. Consequently, several pairs of the gloves were produced to permit more comprehensive field trials. It was found that after delivery of multiple moderately forceful impacts, creasing of the glove frame began to occur close to
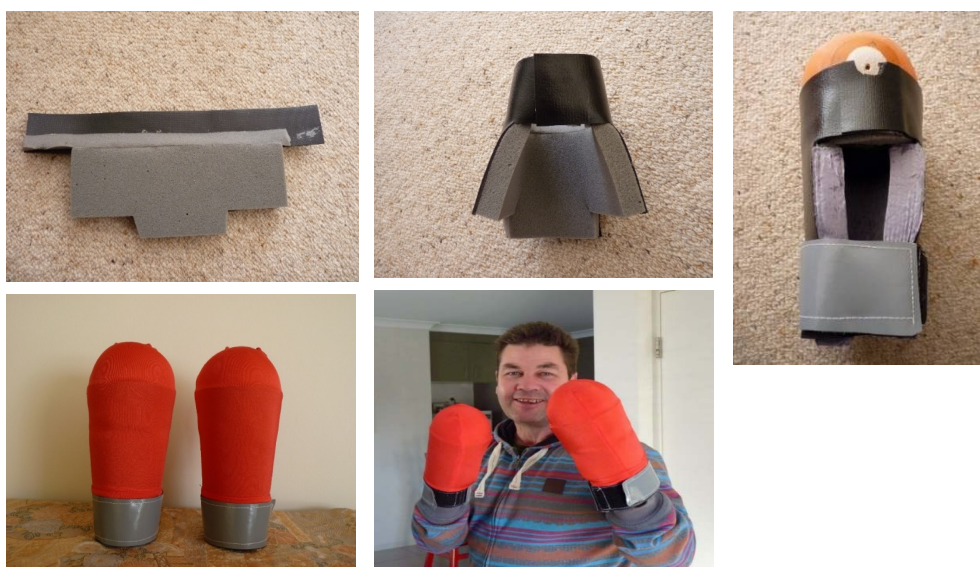

Figure 8. Overview of the construction of the first prototype low-impact gloves designed around the bladder. 
the bottom of the bladder. This area of the frame obviously would be subject to considerable compressive and shear forces during impact.

Investigation of the cause of the creasing problem suggested that it could be due partly to a tendency for the triangular section of foam forming the bladder cradle to become separated from the main (rectangular) section of the glove padding. We therefore made some new prototypes in which the foam element consisted of a single piece, instead of two pieces glued together. We also added a second layer of rubber to the glove frame to increase overall frame strength.

We showed the prototype gloves to colleagues at the University of Canberra and they opined that, in view of the progress made, the time had come to involve a professional industrial designer in the ongoing glove development.

\section{Further Key Enhancements - Greater Visual Resemblance to Conventional Boxing Gloves and More Robust Construction}

In June 2015, a small Canberra-based industrial design business, Stellen Studio, was commissioned to assist with the project. Its Principal recommended that to maximize the appeal of our prototype gloves to potential users, attention should be directed to increasing their visual resemblance to standard boxing gloves. Over the following month, he made several new prototypes consistent with this recommendation (Figure 9). They incorporated no lycra. In each case, the entire glove surface consisted of kangaroo leather, which although less elastic than lycra, has several advantages over bovine leather in that for any given thickness it has much greater tensile strength, is more resistant to stitch tearing, feels softer, is more abrasion-resistant and is less prone to uptake of sweat [53] [54] [55]. Pleating of the joins between the upper and palm sections of the glove meant that there was still reasonable scope for lateral bladder deformation. A port on the under-surface of each glove allowed for inflation and deflation of the bladder with the glove remaining fully intact.

The new prototypes were introduced to participants in the modified boxing program at the Canberra PCYC and the reaction was highly positive. Although the gloves were functionally quite similar to our previous version, they were immediately perceived as superior and there were numerous comments to the effect that we were now "really getting somewhere".

Several pairs of the gloves were made and used in a series of specially organized sparring sessions at the Canberra PCYC. It was found that the gloves seemed to work best when the air pressure within the bladder was only slightly above ambient atmospheric pressure. A Ross Brown model KPCh low-pressure gauge with a range of $0-10 \mathrm{kPa}$ was used to measure bladder air pressure before and after each bout and showed that the bladder valves were resistant to leakage.

With regard to glove comfort, comments from the modified boxing participants were generally favorable and one participant who was a former amateur boxing champion considered them more comfortable than conventional gloves. There were some concerns, however, that they provided less wrist stability and 


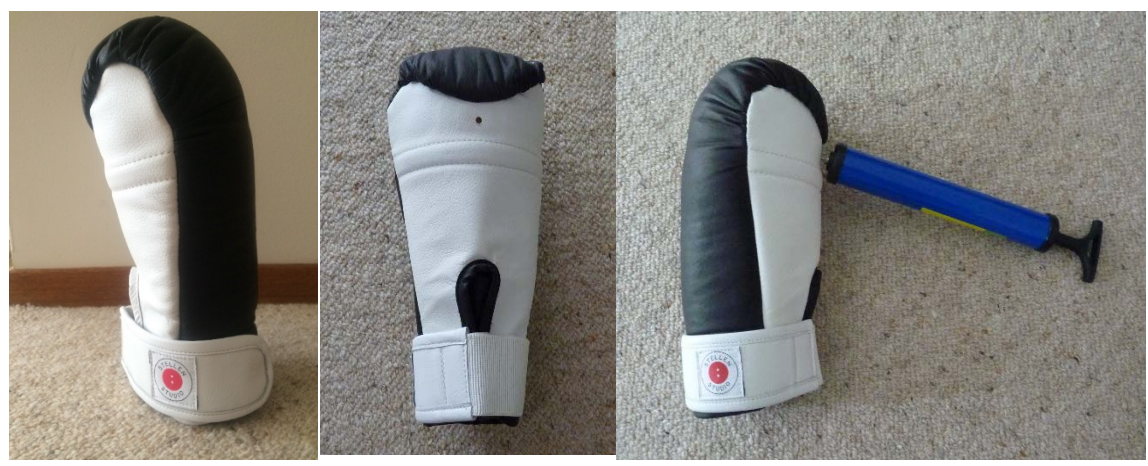

Figure 9. The first prototype low-impact gloves made by Stellen Studio, Canberra, Australia, with mechanism for easy inflation and deflation incorporated.

could therefore predispose to wrist injury. Several athletes indicated that the spherical nature of the bladder could lead to unusual and unexpected glove contact characteristics and that this too might entail risk of injury to the person delivering the contact. There were occasional complaints that the gloves could rotate on the fist during impact.

To address the potential wrist and glove issues, changes to the wrist strap of the gloves were made, particularly in relation to its width. Also, in October 2015, a hemispherical bladder was produced and incorporated into new glove prototypes. The new shape was achieved by using a slightly larger bladder (Enkay India Size 2 soccer ball bladder), then cutting off the its lower third and sealing the hole with a truck tyre patch. The changes enhanced the structural and functional stability of the gloves as well as their visual appeal (Figure 10), and the interest of Canberra PCYC athletes in using the gloves became greater and more sustained than ever before.

At the beginning of 2016 the gloves were used at another AIS Draft Camp for potential boxers. Each of seven aspirants completed two rounds of modified boxing against a former Australian champion amateur boxer. The feedback following the session was very positive. The Coordinator of the Draft Camp advised that the coaches thought the session was "fantastic" and really provided them with an indication of the skill level of the athletes. One of the scientists supporting the camp noted that it was great to be able to gain that indication without need to place the athletes at risk of being hurt.

Of their own volition, three of the aspiring boxers came to speak to us about the gloves, as did the former champion boxer. There was universal agreement that the gloves were very effective in reducing impact forces. A female competitor commented that, upon quickly realizing that there was little possibility she could be hurt, she became more daring in her approach to the sparring. There was an overall feeling that the gloves could be excellent for beginners and a great aid to skill development, although one male athlete noted that, from his own perspective of preparing to participate in conventional boxing, he would rather become accustomed to normal gloves from the outset. Two athletes commented that their hands started to feel slightly uncomfortable due to the need to always 


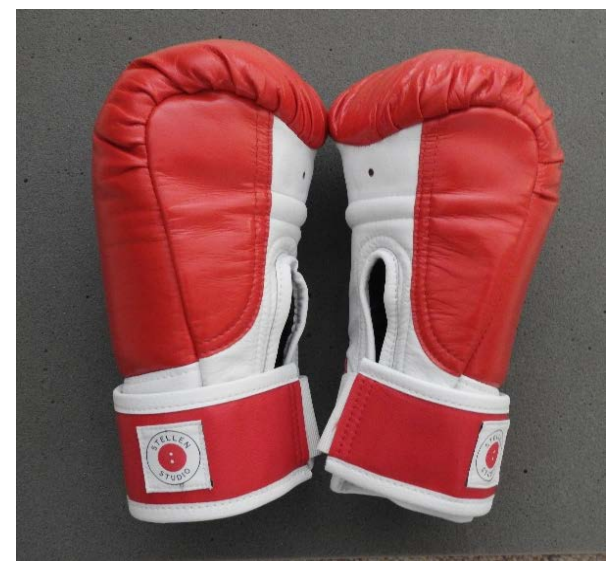

Figure 10. Low-impact gloves with hemispherical bladder, improved wrist support and inclusion of new leather sections providing the gloves with the appearance of having thumb compartments.

keep their fists tightly clenched, but it was recognized that this might have been because the inner gloves that we provided were too small. There was also an impression that the gloves were not tight enough around the wrists. Two athletes advised that they occasionally felt the gloves bend when they delivered hooks or uppercuts. The former national champion boxer, who used the gloves continuously for 14 rounds, said that he found them comfortable throughout, but thought they could be improved by incorporating still larger wrist straps. Examination of the gloves after the session showed that they stood up very well to the stresses, with no damage or deterioration evident.

Shortly after the AIS camp, we conducted another experiment in which three individuals struck the punch testing apparatus at the AIS. Each delivered 10 maximal punches to the wall-mounted, padded force plate with both left and right hands, and with each of three different glove types-prototype low-impact gloves with a bladder pressure of $2.0 \mathrm{kPa}$, conventional $10 \mathrm{oz}$ (Std 10oz) gloves and conventional $160 \mathrm{oz}$ (Std 16oz) gloves. The order in which the glove types were used was varied between individuals. Within each set of 10 punches, the interval between punches was $20-30$ seconds. The intra-subject interval between sets was 15 - 20 minutes.

One of the participants in the experiment was a male former Australian amateur boxing champion, another was a female participant in the modified boxing program at the Canberra PCYC, and the third was a 64-year old male who is one of the authors of this paper.

The results of the experiment are shown in Figure 11. The variability in peak force readings within sets was greater with the prototype low-impact gloves than with the conventional gloves, particularly in the case of the former champion boxer. To avoid the possibility of this greater variability giving a falsely elevated impression of the protective effect of the prototype gloves, it was decided to confine comparisons to the single highest readings recorded by each of the athletes under the various conditions. This approach showed that, for the female and the 


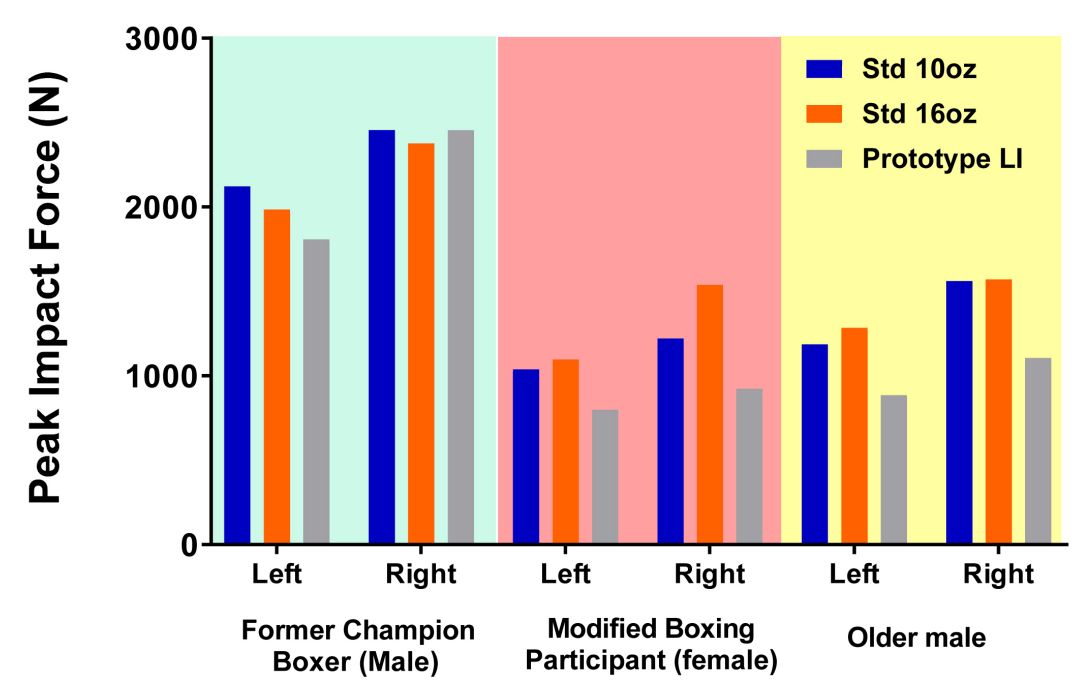

Figure 11. Effect of glove type on peak force recorded on punch integrator by three different subjects. Each column represents the highest single reading recorded from 10 attempts.

older male participant, the prototype low-impact gloves reduced peak impact force by $22 \%-31 \%$ compared with Std $10 \mathrm{oz}$ gloves. For the former national champion boxer, who generated much higher absolute peak force levels, there was a reduction of $\sim 15 \%$ for the left [non-dominant] hand but almost no reduction $(1.5 \%)$ for the right hand.

The findings were interpreted as suggesting that while the prototype low-impact gloves could substantially reduce peak forces associated with even moderately heavy impacts, they became ineffective when impacts when were very heavy, presumably because maximum compression of the bladder had been approached. A need was apparent, however, for a testing method less dependent on human factors and more suitable for allowing quantitative assessment of the gloves across a wide range of controlled impact magnitudes.

\section{Progression in Glove Evaluation}

In accordance with standard practice, we had used a pendulum system to check the calibration of the AIS punch-testing apparatus. This entailed releasing a steel pendulum arm with a length of 1 metre and a mass of $9.4 \mathrm{~kg}$ from a horizontal position so that a hammer on the end of the arm struck the centre of the force plate padding when the arm reached the vertical position. It was known that for the particular apparatus this process should yield a peak force reading of $\sim 1,500$ $\mathrm{N}$. It occurred to us that adapting the pendulum to enable fitting of different glove types to its hammer end could provide a means for enabling repeatable evaluation of the influence of the gloves on peak impact forces.

To implement this approach, we needed to develop a "mechanical fist" that could be attached to the pendulum and provide for the addition of known masses to the pendulum arm to permit generation of peak impact forces at least as high as those produced by elite boxers. It was also necessary to modify the 
frame supporting the pendulum arm so that the swivel point of the arm could be further away from the target, such that the arm with mechanical fist and glove attached would still be vertical when impact to the target occurred. Additionally, the position of the swivel point had to be adjustable to cater for different glove lengths.

There was a requirement for the mechanical fist to be designed in a way that allowed its insertion into gloves to properly simulate real-world practice for different glove types. This meant that it had to cater for conventional gloves to be put on with fingers extended, and the fist subsequently clenched, and for prototype low-impact gloves to be put on with the fist already in the clenched position. With assistance from a Senior Technical Officer at the University of Canberra, we designed a mechanical fist with the necessary characteristics and arranged for a local engineering company to build it to our specifications. The device is shown in Figure 12.

At the same time a new pendulum arm was produced that had a mass of 5.54 $\mathrm{kg}$ and provided for screw attachment of the mechanical fist at one end (at $90^{\circ}$ to the shaft of the arm) and for placement and securing of extra masses behind the fist on the other side of the shaft. A metal sleeve was manufactured to enable extension of the frame providing the swivel point for the pendulum. The sleeve incorporated a series of holes to cater for alteration of the swivel point.

The first tests with the new method (see Figure 13) produced some valuable data. When we used the pendulum arm with no additional weight added, the mean peak force ( \pm standard deviation) for eight releases of a Std $10 \mathrm{oz}$ glove from a horizontal position was $1241 \pm 8 \mathrm{~N}$, and in a repeat test involving $14 \mathrm{re}$ leases it was $1247 \pm 9 \mathrm{~N}$. Under the same conditions, a prototype low-impact glove with a bladder pressure of $2.0 \mathrm{kPa}$ gave a mean peak force of $997 \pm 19 \mathrm{~N}$, a reduction of $\sim 20 \%$. With $5 \mathrm{~kg}$ of weight added to the pendulum, the mean peak force for 12 releases of the Std $10 \mathrm{oz}$ glove was $1878 \pm 17 \mathrm{~N}$. For the prototype low-impact glove (also across 12 releases) it was $1249 \pm 26 \mathrm{~N}$, a reduction of $33.5 \%$.

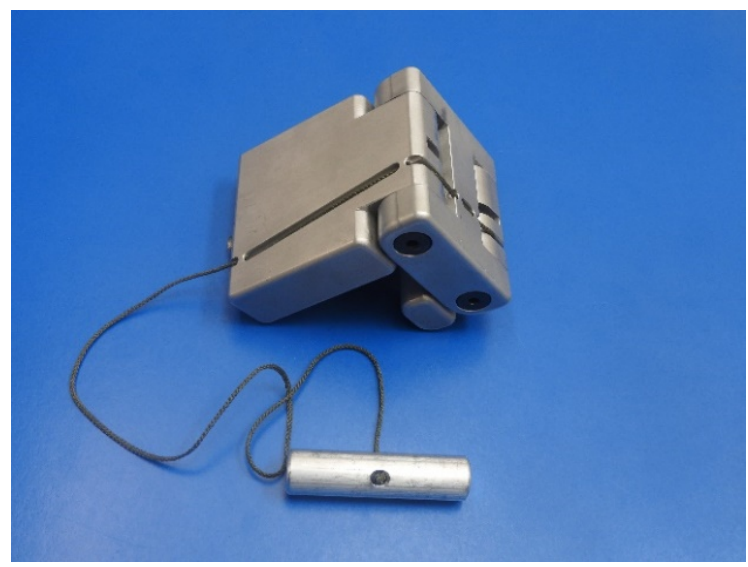

Figure 12. A first-prototype mechanical fist manufactured for glove testing. The cable could be pulled to draw the device into a position simulating the position of an open hand for insertion into a conventional glove. 


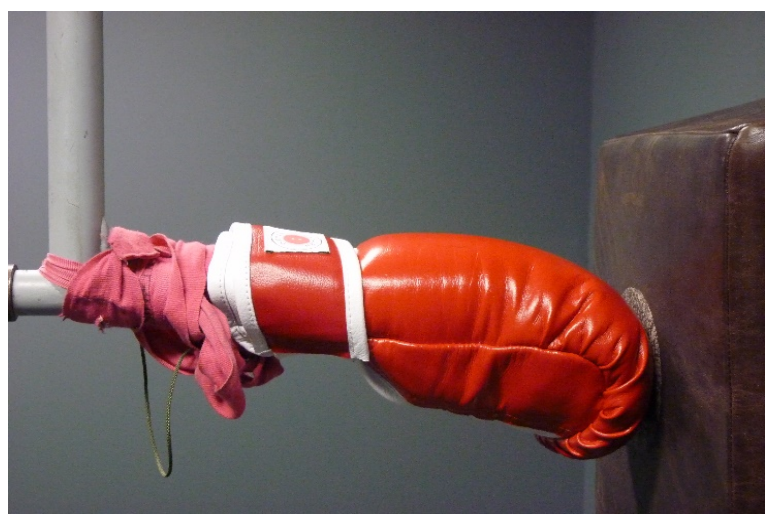

Figure 13. First tests involving use of a pendulum apparatus with attached mechanical fist for glove testing. The photograph shows a prototype low-impact glove contacting the pad covering the wall-mounted force plate.

The variability in peak force measurements associated with any given condition was very much less than in our prior human trials. Nevertheless, some problems were encountered in the conduct of the experiment. The fit of the mechanical fist into the gloves was sub-optimal, necessitating minor modification of the gloves to ensure achievement of the desired fist position within them. The bar for addition of masses to the pendulum proved to be slightly too small in diameter and had to be taped to prevent the $5 \mathrm{~kg}$ mass used in the trial from moving. With the heavier impacts the prototype low-impact glove seemed first to deform and then "buckle under". This was perhaps because the centre of mass of the mechanical fist was somewhat below the long axis of the "wrist"-a situation differing from the real world. Most importantly of all, it proved difficult to maintain the mechanical fist in a fully clenched position inside the Std $10 \mathrm{oz}$ glove, preventing continuation of the experiment to include very high impact magnitudes.

To address the shortfalls of the initial mechanical fist, a new one was designed and built by a Melbourne-based team consisting of an engineer and an aircraft mechanic. It incorporated a ratchet system for clenching the fist and locking it firmly in the clenched position. The mass of the fist was distributed around the long axis of the unit rather than being largely below it (Figure 14). The pendulum was modified to increase the robustness of its connection to the fist.

In February 2016, a trial entailing use of the new mechanical fist was conducted (Figure 15). Initially, we compared a Std $12 \mathrm{oz}$ glove to a prototype low-impact glove with the bladder inflated to a pressure of $2.0 \mathrm{kPa}$. Both gloves were new. In each case, a $10 \mathrm{~kg}$ mass was attached to the pendulum and the glove was successively released to travel through $\operatorname{arcs}$ of $15^{\circ}, 30^{\circ}, 45^{\circ}, 60^{\circ}$ and $75^{\circ}$ as measured using a digital goniometer (Imex EL Series EL-20). There were 20 releases per glove per pendulum arc.

The results of the experiment are shown in Table 1.

We had intended to proceed also to a pendulum arc of $90^{\circ}$ but the pendulum frame began to show signs of damage so the trial had to be discontinued and 


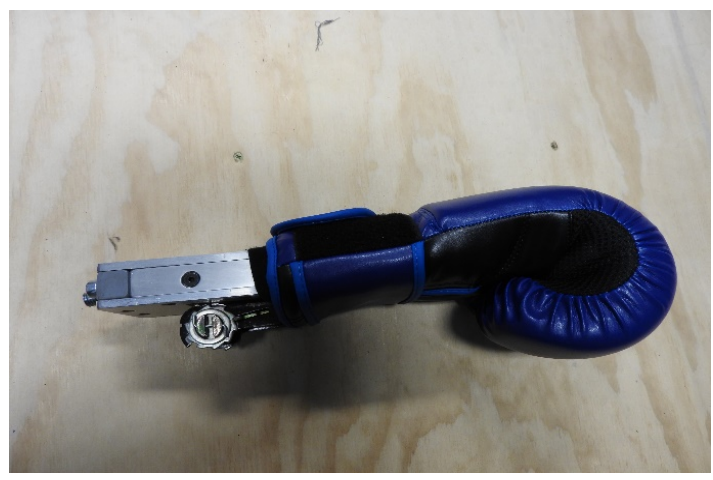

Figure 14. A conventional glove attached to the new mechanical fist, with the fist locked into the clenched position through use of a ratchet mechanism.

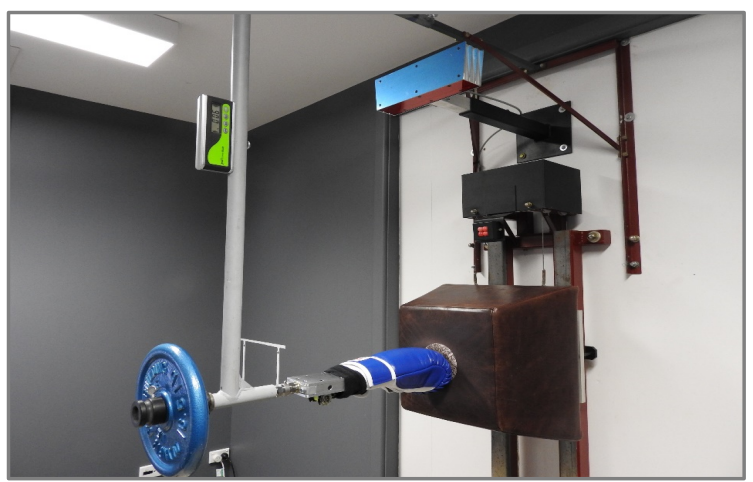

Figure 15. Glove testing using the pendulum apparatus, the new mechanical fist and the wall-mounted force plate at the Australian Institute of Sport. The digital goniometer used to measure pendulum release angles can be seen on the pendulum shaft.

Table 1. Effect of glove type and pendulum arc on peak impact force. For each condition, mean peak force for 20 trials is shown, along with the associated standard deviation.

\begin{tabular}{cccc}
\hline Pendulum Arc & Std 12oz glove & $\begin{array}{c}\text { Prototype } \\
\text { Low-impact glove }\end{array}$ & $\begin{array}{c}\text { \% Reduction In } \\
\text { Peak Force }\end{array}$ \\
\hline $15^{\circ}$ & $249 \pm 3 \mathrm{~N}$ & $190 \pm 4 \mathrm{~N}$ & 23.7 \\
$30^{\circ}$ & $541 \pm 7 \mathrm{~N}$ & $394 \pm 8 \mathrm{~N}$ & 27.1 \\
$45^{\circ}$ & $927 \pm 19 \mathrm{~N}$ & $675 \pm 7 \mathrm{~N}$ & 27.2 \\
$60^{\circ}$ & $1344 \pm 14 \mathrm{~N}$ & $1038 \pm 34 \mathrm{~N}$ & 22.8 \\
$75^{\circ}$ & $1772 \pm 11 \mathrm{~N}$ & $1567 \pm 31 \mathrm{~N}$ & 10.7 \\
\hline
\end{tabular}

temporary repairs implemented. The repairs involved stabilizing the pendulum mounting bar at its outer end to take the pressure off the support frame.

Further analysis of the data collected up to that point showed that using just the first five of the 20 releases under each condition would scarcely have changed the mean values. Accordingly, after the repairs we carried out a further experiment in which five different gloves types were compared-Std 10oz, $12 \mathrm{oz}$ and $160 \mathrm{z}$ gloves, an inexpensive recreational $10 \mathrm{oz}$ glove, and a prototype low-impact glove with the bladder inflated to a pressure of $2.0 \mathrm{kPa}$-but this time each glove was dropped only five times through each arc. The arcs were as 
above and a $10 \mathrm{~kg}$ added mass was again employed.

The results of this follow-up experiment appear in Figure 16. In terms of the peak forces recorded with the various pendulum arcs, the Std 10oz, $12 \mathrm{oz}$ and $16 \mathrm{oz}$ gloves and the cheap recreational $10 \mathrm{oz}$ glove were virtually indistinguishable from one another. The readings for the prototype low-impact gloves were $15.9 \%, 19.9 \%, 22.3 \%, 12.7 \%$ and $6.3 \%$ lower than the mean value for the other four glove types for the pendulum arcs of $15^{\circ}, 30^{\circ}, 45^{\circ}, 60^{\circ}$ and $75^{\circ}$ respectively. The differences between the Std $12 \mathrm{oz}$ glove and the prototype low-impact glove were less than those observed earlier, due to the peak force readings being slightly lower for the former and slightly higher for the latter. This may have been due to subtle changes introduced by the repairs to the pendulum support structure, and highlights the potential for research outcomes to be influenced by seemingly minor adjustments to experimental apparatus. Nevertheless, the general trend that we had observed in the earlier experiment was essentially confirmed, with the low-impact glove producing considerable reductions in impact force when impact forces were low to moderate but showing diminished effectiveness at higher impact forces.

We began to wonder whether the protective effect of our prototype low-impact glove was being influenced by the relationship between the pre-impact velocity and the effective mass of the striking object. Figure 17 shows that, even for the best-case scenario associated with our addition of a $10 \mathrm{~kg}$ weight to the pendulum arm used with the AIS punch testing system, fitting of a curve to the relationship between peak force measured with the Std $12 \mathrm{oz}$ glove and the reduction in peak force achieved with the low-impact glove suggested that the protective effect would fall below $20 \%$ when the peak force for the Std $12 \mathrm{oz}$ glove exceeded $\sim 1453 \mathrm{~N}$ and would disappear altogether at $2053 \mathrm{~N}$. However, protective effects considerably exceeding these predictions were observed in our earlier experiments involving the addition of only a $5 \mathrm{~kg}$ weight to the pendulum or human delivery of maximal punches.

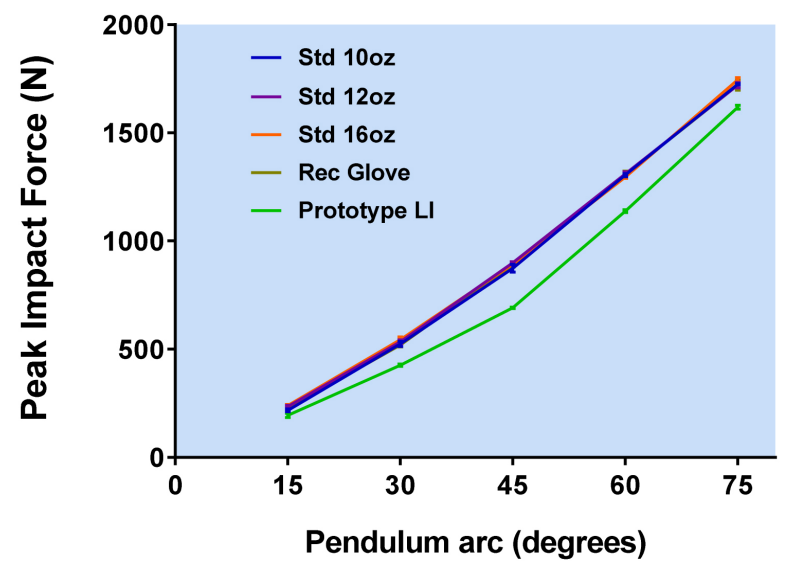

Figure 16. Effect of glove type on peak impact force in force plate testing involving release of weighted pendulum from various heights. Each data point is the mean of five pendulum releases. 


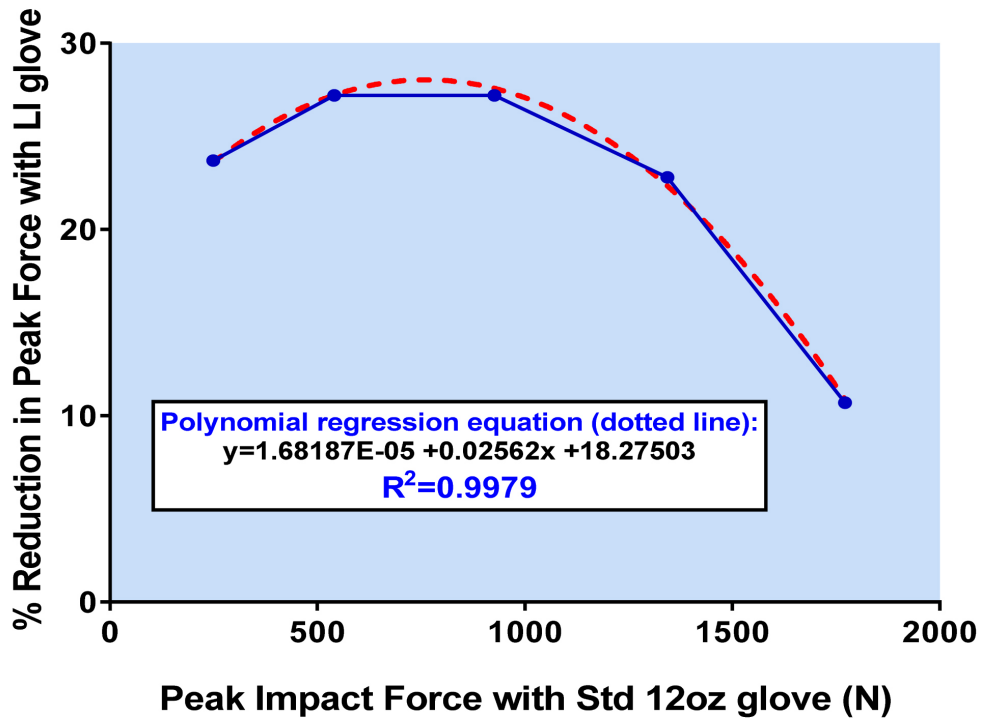

Figure 17. Effect of Low-Impact Glove on \% peak force reduction as a function of peak force magnitude. The solid line joins observed data points. The dotted line is a curve fitted to the data through a second-order polynomial regression equation.

Release of our 1-metre long pendulum to travel through an arc of $75^{\circ}$ resulted in a pre-impact velocity of $\sim 3.8 \mathrm{~m} \cdot \mathrm{sec}^{-1}$ and addition of a $10 \mathrm{~kg}$ mass to the pendulum provided a total effective mass of $\sim 18.5 \mathrm{~kg}$, whereas Walilko et al. [56] have reported that the peak pre-impact glove velocity attained by seven elite boxers averaged $9.14 \mathrm{~m} \cdot \mathrm{sec}^{-1}$ and the effective mass averaged only $2.9 \mathrm{~kg}$. It seemed reasonable to imagine that vastly different approaches to generation of impact forces might affect impact contact times and the ability of specific structures to buffer the forces. We therefore perceived a need to develop a laboratory-based glove testing method that was more closely aligned to real-world conditions.

\section{A Step toward Greater Ecological Validity}

After evaluating several options, it was decided that the best approach would be to carry out straight drop test experiments involving the dropping of gloves from known heights on to an in-floor force plate. We determined that to reproduce the glove velocities that Walilko et al. [56] found elite boxers capable of generating we would need to drop gloves from a height of close to 5 metres. We were able to access a University of Canberra laboratory with a $600 \mathrm{~mm} \times 400 \mathrm{~mm}$ in-floor Kistler force plate (Kistler, Amherst, MA, USA) and a ceiling height that made glove drops from up to 5 metres possible. A wall-mounted metal frame supporting a low-friction, flanged pulley was constructed and affixed to a wall of the laboratory such that the pulley was located directly above the centre of the force plate a height of 5.5 metres. Gloves could be drawn up to any required drop height by means of a cord placed over the pulley. The cord was manually pulled through an eyelet positioned at the top of a floor-mounted post. It was marked at intervals corresponding to 0.5 metre increments in drop heights between 1 and 5 metres. Alignment of the marks with the eyelet on the post en- 
sured accuracy of the drop heights.

The mechanical fist employed in our final pendulum experiments was modified so that a high-tensile steel rod could be securely screwed into it at the end opposite that designed to receive the gloves. At the other end of the rod was a hook for attachment of the cord. With the rod incorporated, the mechanical fist had a mass of $3.046 \mathrm{~kg}$ which was close to the $2.9 \mathrm{~kg}$ found to be the average effective mass associated with maximal punches delivered by elite boxers [56]. A photograph of the experimental configuration appears in Figure 18.

A pilot trial with the new drop testing system was conducted in early April 2016. A Std $10 \mathrm{oz}$ boxing glove and a prototype low-impact glove with a bladder pressure of $2.0 \mathrm{kPa}$ were each dropped ten times on to the force plate from heights of 1, 1.5, 2, 2.5 and 3 metres. The force plate was unpadded and its outputs were monitored at a rate of $3000 \mathrm{~Hz}$ using Kistler Bioware software run on a standard PC. Throughout the testing session, known masses were regularly placed on the force plate to check the accuracy of the force plate readings. The results of the pilot trial are shown in Figure 19.

We were greatly surprised by the magnitudes of the peak force readings, with the conventional glove producing a mean peak force reading of more than 3000 $\mathrm{N}$ even when the drop height was only 1 metre. This finding was considered due to the absence of protective padding over the force plate and the resultant lack of "give" in the target. It served to emphasize the importance of target characteristics in the determination of peak force readings. Detailed analysis of the data revealed that, at the higher drop heights, rise in force readings was so rapid that a sampling rate of $3000 \mathrm{~Hz}$ was insufficient to ensure precise identification of peaks. The most important finding, though, was that while the prototype

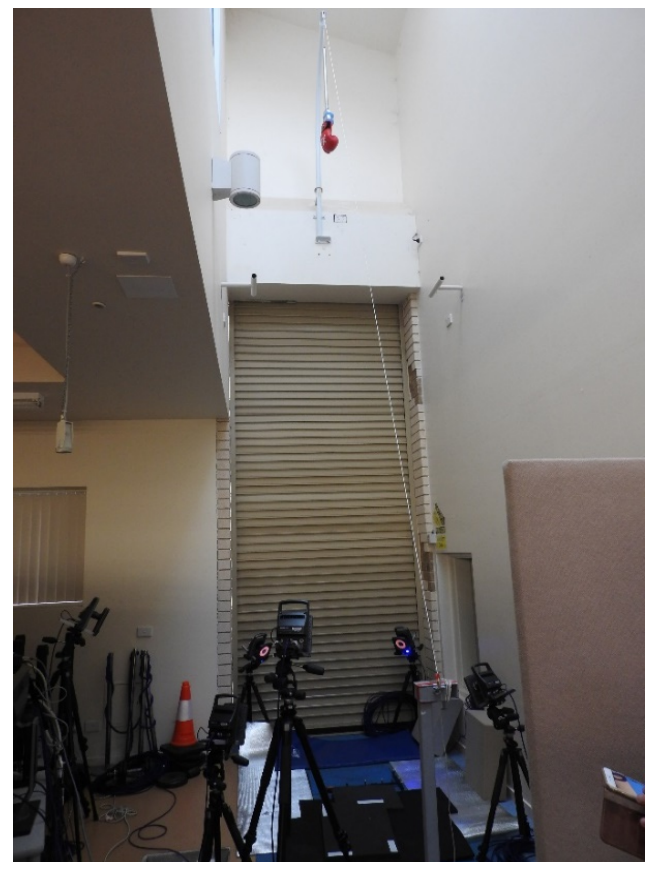

Figure 18. Drop testing system used for glove evaluation at the University of Canberra. 
low-impact glove substantially reduced peak forces associated with drop heights of $1,1.5$ and 2 metres and still offered some protection at 2.5 metres, there was no protective effect at 3 metres. Since the peak forces with a drop height of 3.0 metres were in the vicinity of $12,000 \mathrm{~N}$ which is far above the level reportedly generated by boxers [47], the real-world implications of the finding were unclear. Even so, examination of force curves was undertaken and revealed that although the low-impact glove always served to delay the onset of rapid increase in force, the shape of the curves beyond that onset became progressively more similar for the two glove types as drop height increased. At 3 metres, the shapes were very similar indeed (Figure 20).

This suggested that the low-impact glove had reached a point of maximum bladder compression beyond which it began to act like a conventional glove. In view of the insights gained from the pilot work, it was resolved that in subsequent

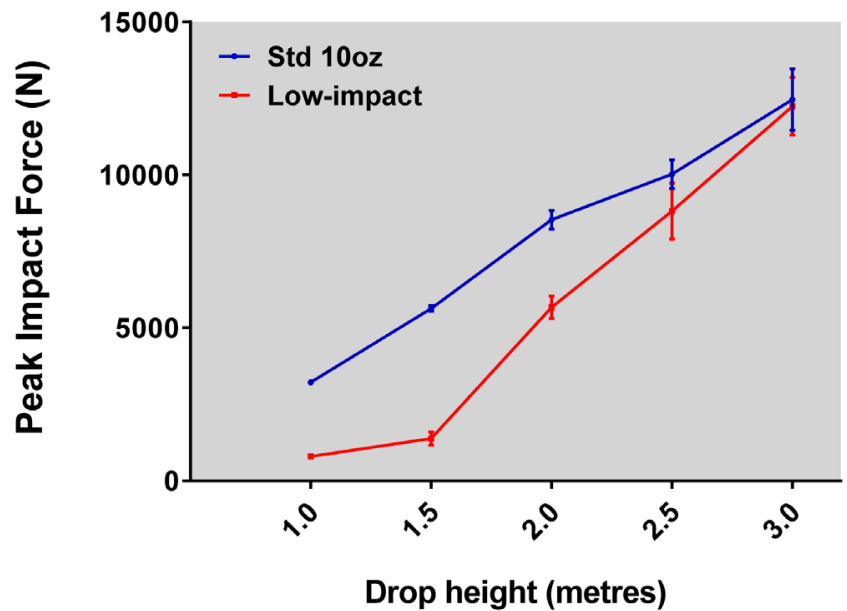

Figure 19. Effect of drop height on mean peak impact force recorded with prototype low-impact and standard $10 \mathrm{oz}$ boxing gloves dropped on to an unpadded force plate.

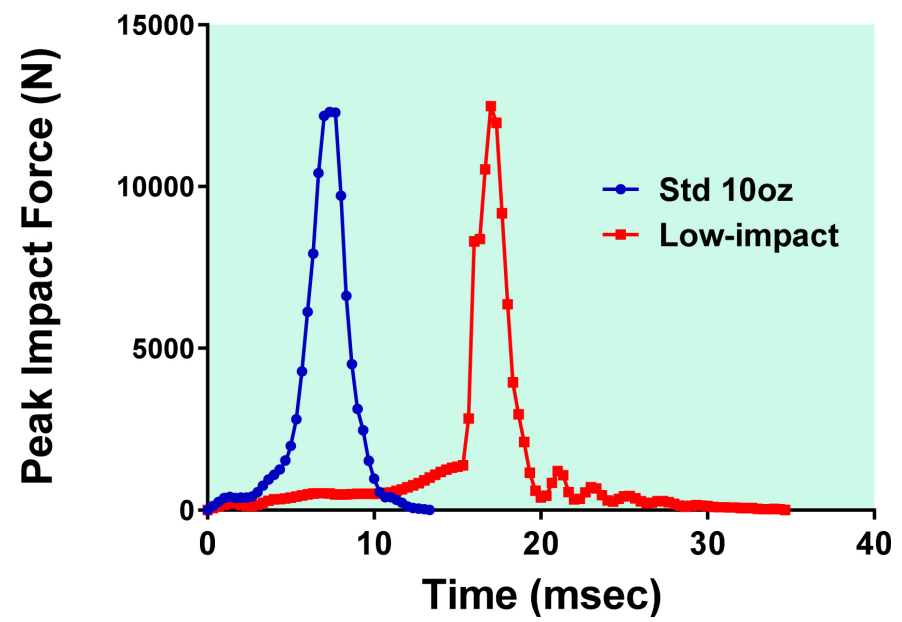

Figure 20. Force-time curves for standard $10 \mathrm{oz}$ and prototype low-impact gloves dropped on to an unpadded force plate from a height of 3 metres. The force plate sampling rate was $3000 \mathrm{~Hz}$. 
drop testing some padding should be placed over the force plate and the sampling rate should be increased. Critically, a decision was also made to develop a new prototype glove that permitted occurrence of some air release from the bladder when pressure within the bladder became high. This meant a return to the first idea that we had explored, but now with a different glove configuration, different materials, and insights gained in the intervening period. It was reasoned that capacity for some air release should decrease the rate of pressure build-up, thereby changing the effect of heavy impacts on the shape of the force curve and yielding lower peak force readings.

\section{A New Prototype Glove Incorporating Air Release}

It was clear that any glove incorporating a bladder with capacity for air release during impact would need to also have a mechanism for rapid return of the air following impact release. We mooted the possibility of achieving this through inclusion of separate one-way valves for air outflow and inflow, as described in the patent registered by Carrillo [46], but eventually settled on a solution that we considered simpler and less susceptible to failure.

In our design there was a single hole in the bladder. The bladder was provided with a resilient, elastic internal "skeleton" that could collapse under conditions of high internal pressure during impact but would immediately recover its shape thereafter, with the recovery causing the internal bladder pressure to fall temporarily below the ambient pressure, so driving air inflow. With this approach, no valves were required.

Figure 21 shows our first prototype of the new bladder. The internal skeleton consisted of a "ball" of high-density, medium-firmness open cell foam (Joyce Foam Products HR 36 - 140), which was placed inside the bladder prior to sealing with the truck tyre patch. A hole was then made in the bladder and a plastic tube with an internal diameter of $10 \mathrm{~mm}$ was inserted. The area around the insertion was then sealed.

The next step was manufacture of a new prototype glove containing the modified bladder, which was positioned in a way that allowed location of the air vent on the palmar surface of the glove (Figure 22).

\section{Comparison of Gloves through Drop Testing}

In late April 2016, we conducted a study in which the drop testing apparatus was used to compare a Std $10 \mathrm{oz}$ glove, a Std $16 \mathrm{oz}$ glove, a prototype low-impact glove with a sealed bladder (SBLI), and the new prototype low-impact glove with air release capability (ARLI).

This experiment is described in detail elsewhere [57]. Briefly, each glove was dropped on to the force plate 10 times from each of nine different heights ranging from 1 to 5 metres. The glove weights, as measured by digital kitchen scales, were $278 \mathrm{~g}, 455 \mathrm{~g}, 227 \mathrm{~g}$ and $298 \mathrm{~g}$ for the Std 10oz, Std 16oz, SBLI and ARLI gloves respectively. The force plate was covered by a $25 \mathrm{~mm}$ thick mat of Ultralon 


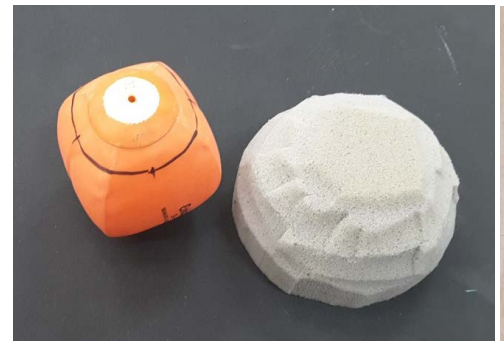

(a)

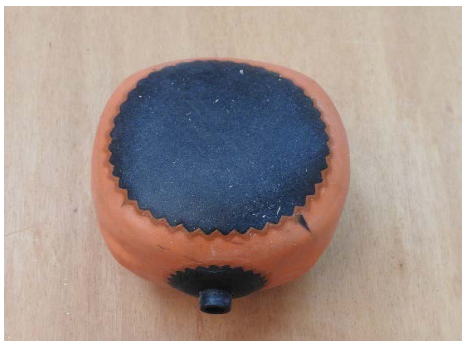

(b)

Figure 21. Construction of bladder for new prototype low-impact glove with capability for air release. The Size 1 soccer ball bladder in panel a was cut cross-sectionally at the point indicated by the black line. The foam skeleton was then inserted and the unit was sealed with a truck tyre patch (panel b). A port allowing air release and reuptake was then added.

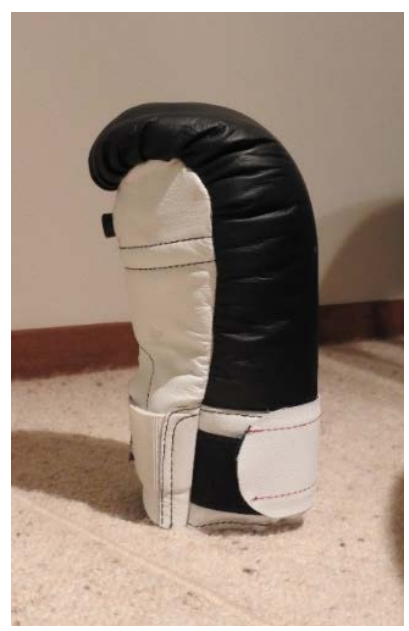

Figure 22. Prototype low-impact glove allowing movement of air between glove bladder and external environment. The port for air exchange can be seen on the front surface of the glove.

EVA 75 material (Ultralon Foam Group, Sydney, Australia) with a guaranteed Shore A durometer hardness rating of 30 - 35, which is at the upper end of the range for healthy human skin but well below the level for human bone [58] [59]. Outputs from the force plate were sampled at 10,000 Hz. The results are summarized in Figure 23.

The covering of the force plate with the EVA mat caused peak force readings to be lowered by approximately half compared to those recorded in the pilot trial when no such covering was employed. Compared to the Std $10 \mathrm{oz}$ and Std $16 \mathrm{oz}$ gloves, the two pneumatic gloves reduced peak impact force by approximately the same amount up to and including a drop height of 2.5 metres. Beyond that point, the performance of the ARLI glove was superior. At drop heights of 4, 4.5 and 5 metres, the SBLI glove was essentially no longer protective, whereas peak impact forces observed with the ARLI glove were lower than those seen with the Std $10 \mathrm{oz}$ glove by just over $30 \%$. An even greater effect was seen in relation to the peak rate of force development, which was calculated by determining the 
largest increase in peak force over any running period of $0.5 \mathrm{msec}$, then doubling the result to obtain a reading in $\mathrm{N} \cdot \mathrm{msec}^{-1}$. With the ARLI glove, the reduction in peak rate of force development relative to the Std $10 \mathrm{oz}$ glove was $\sim 60 \%$ at drop heights up to and including 3.5 metres and 55\%,50\% and $47 \%$ at drop heights of 4, 4.5 and 5 metres respectively. The SBLI glove was nearly as effective as the ARLI glove in decreasing the peak rate of force development at 1 and 1.5 metres, but its effectiveness then progressively reduced, and at 4, 4.5 and 5 metres it produced readings exceeding those for the Std $10 \mathrm{oz}$ and Std $16 \mathrm{oz}$ gloves.

Both pneumatic gloves increased contact times between glove and target (Figure 24), allowing distribution of impact energy over a longer period.

It is evident, however, that when impact energy was high, air within the sealed bladder of the SBLI glove approached and perhaps even reached maximum compression, causing the glove to become hard and peak force to then undergo rapid increase.

In Figure 25, force-time curves are presented for each of the different gloves
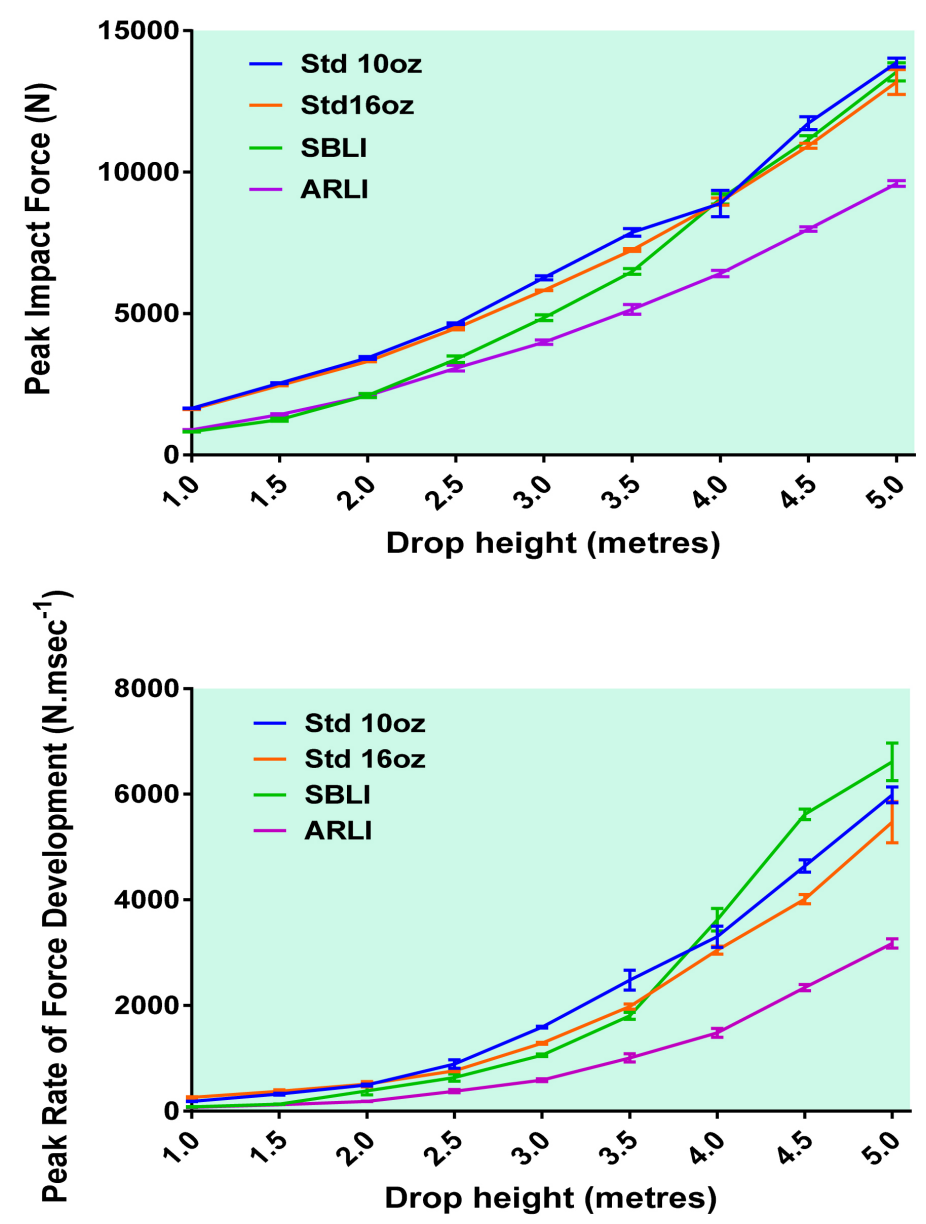

Figure 23. Peak impact forces and peak rates of force development as a function of glove type and drop height. Each point on the graphs is the mean of the highest five readings recorded in a series of 10 drops. The bars show standard deviations for the five drops. Std $10 \mathrm{oz}=$ conventional $10 \mathrm{oz}$ boxing glove, Std $16 \mathrm{oz}=$ conventional $16 \mathrm{oz}$ boxing glove, SBLI = Pneumatic glove with sealed bladder, ARLI = Pneumatic glove with air release. 


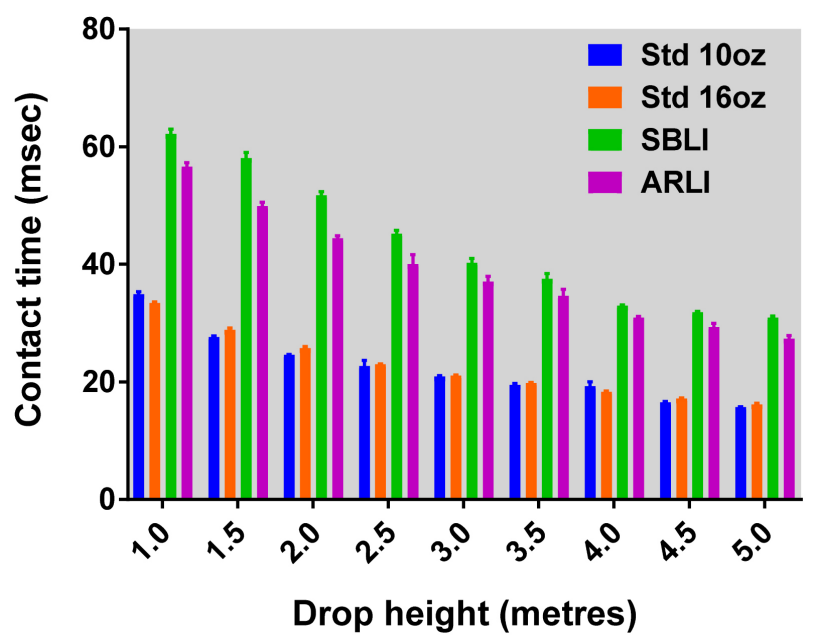

Figure 24. Force plate contact times for different glove types and drop heights. Each bar represents a mean value for five glove drops that produced the highest peak impact forces within a series of 10 drops. Standard deviations for the five drops are also shown.
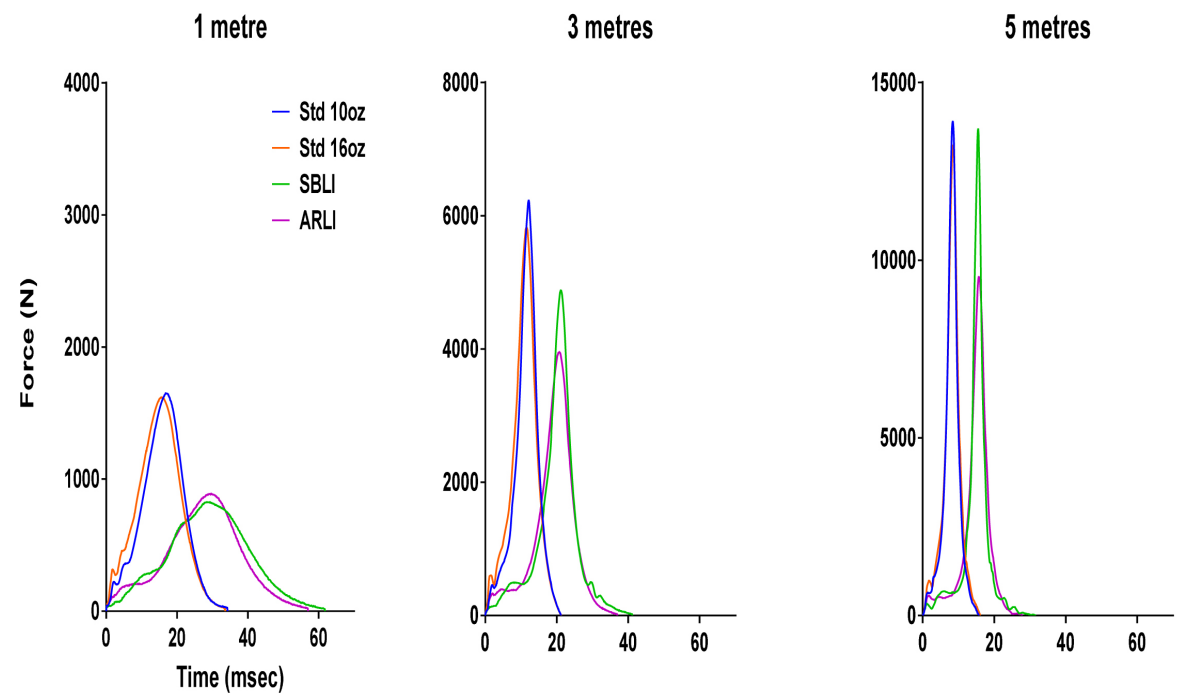

Figure 25. Force-time curves for different glove types at selected drop heights. Note that the scale on the vertical axis differs between the three panels.

at drop heights of 1, 3 and 5 metres. Each curve relates to the glove drop that produced the third highest peak force reading from 10 drops under the specified condition (i.e. the median peak force from the highest five readings obtained). The trend evident in the Figure is representative of that observed across all nine drop heights. The impact-damping capacity of the SBLI glove eventually 'bottomed out' as drop height increased, while that of the ARLI glove was maintained.

Overall, the results of the experiment clearly suggested that future efforts should be concentrated on refining the ARLI glove, since only this glove proved capable of providing significant protection across the whole spectrum of impact magnitudes assessed. 


\section{Experimentation with Hole Pattern for Air Exchange and Importance of Bladder Foam Density}

It was evident that in an air-release glove intended for field use, there could be no projection of an air pipe beyond the palmar surface of the glove. After considering various possibilities for a more practical air transport pathway, we produced some bladders that each incorporated six small air openings rather than a single larger one, with the openings extending only to the glove surface. Effort was made to ensure that their total cross-sectional area was similar to that of the air channel in our original ARLI glove. There was an obvious need to test the effectiveness of the new arrangement. We also wanted to determine the extent to which characteristics of the foam forming the bladder skeleton could influence the performance of the glove when the nature of the air openings was held constant.

To enable achievement of the above dual purposes, we manufactured three new ARLI gloves, all with the six-hole system for air exchange. In one of these gloves, the bladder contained a relatively soft, high-density open cell urethane foam (Dunlop HR 36 - 80). In another, a relatively firm high-density open cell urethane foam (Dunlop HR 38 - 200) was employed. The firm open cell urethane foam was incorporated also into the third of the new gloves, but as a series of small blocks or "crumbs" rather than as a single, hemispherical piece. It was reasoned that use of crumbed foam would increase the total air content of the bladder and that this might positively influence the impact-damping qualities of the glove.

In June 2016, we conducted an experiment in which the three new gloves were compared, and in which our original ARLI glove and a Std 10oz glove were also included for reference purposes. The gloves used in the experiment are pictured in Figure 26. The Std $10 \mathrm{oz}$ glove had a mass of $278 \mathrm{~g}$ and the original ARLI glove had a mass of $298 \mathrm{~g}$. The gloves with the soft open cell urethane foam, firm open cell urethane foam and crumbed firm open cell urethane foam had masses of $264 \mathrm{~g}, 288 \mathrm{~g}$ and $241 \mathrm{~g}$ respectively.

Each glove was dropped on to the force plate 10 times from heights of 1, 2, 3, 4 and 5 metres. The force plate was again covered with a mat of EVA 75 foam with a thickness of $25 \mathrm{~mm}$. The Std $10 \mathrm{oz}$ glove was tested first, followed by the original air-release glove (Original ARLI), then the gloves with bladders consisting of the soft high-density open cell urethane foam (Soft Foam), a single piece of firm high-density open cell urethane foam (Firm Foam) and multiple pieces of firm high-density open cell urethane foam (Crumbed Foam). For each glove, the initial drop height was 3 metres, followed by 4,5 and 2 metres and finally 1 metre. Figure 27 shows the peak impact forces recorded.

All the low-impact glove prototypes diminished the peak forces compared to the Std $10 \mathrm{oz}$ glove, but at drop heights of 3 metres and above, the Soft Foam prototype was the least effective of them. The Firm Foam and Crumbed Foam gloves reduced peak impact forces to much the same extent as the Original ARLI 


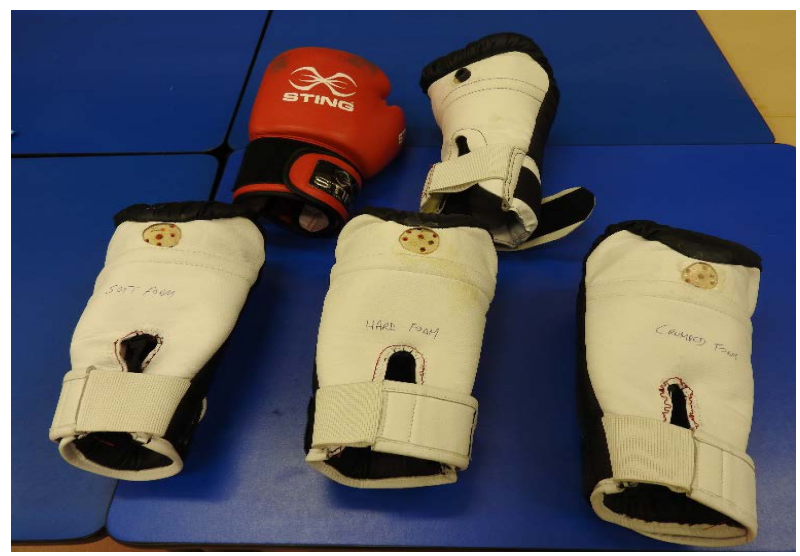

Figure 26. Gloves used in testing the effects of a new pattern of air openings and variation in foam characteristics of the bladder skeleton on the impact damping performance of ARLI gloves.

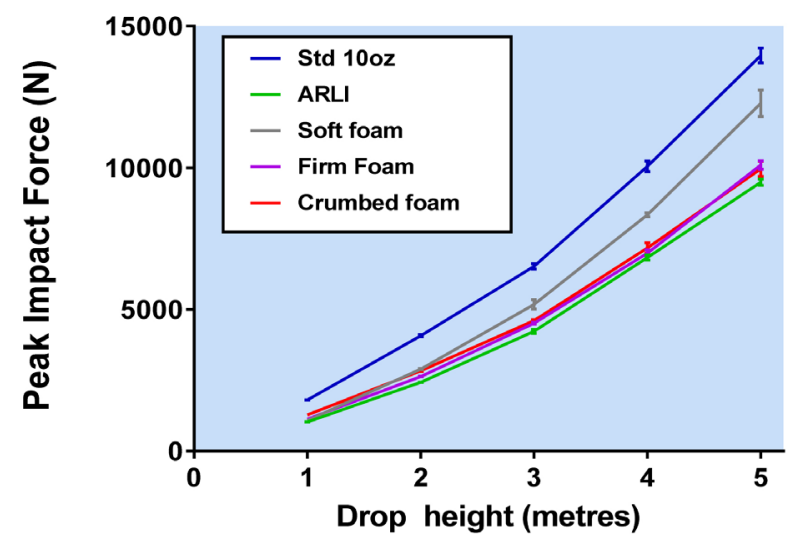

Figure 27. Effect of glove type and drop height on peak impact force. Each point represents the average of the highest five readings from 10 drops under the specified condition and the bars show standard deviations of the five readings. The force plate sampling rate was $10,000 \mathrm{~Hz}$.

glove, although the latter was associated with slightly lower readings at all drop heights. Peak impact forces observed with the Original ARLI glove were $\sim 43 \%$, $40 \%, 35 \%, 32 \%$ and $32 \%$ less than those for the Std $10 \mathrm{oz}$ glove at drop heights of $1,2,3,4$ and 5 metres respectively. This was consistent with the findings of our earlier testing.

With all the prototype low-impact gloves, the onset of rapid rise in force after contact was delayed compared to that associated with the Std $10 \mathrm{oz}$ glove (Figure 28). The delay was related to the firmness of the foam, being longest with the softer foam and shortest for the two gloves incorporating the firmer foam. This suggests that the period for which glove deformation was the primary determinant of the force-time curve increased as the firmness of the foam decreased. However, it seems likely that the peak force reached in the succeeding phase of the interaction between glove and target was influenced by the amount of air remaining available for expulsion during that period. Since at drop heights of 3 metres and upwards the Firm Foam and Crumbed Foam gloves were more 
1 metre

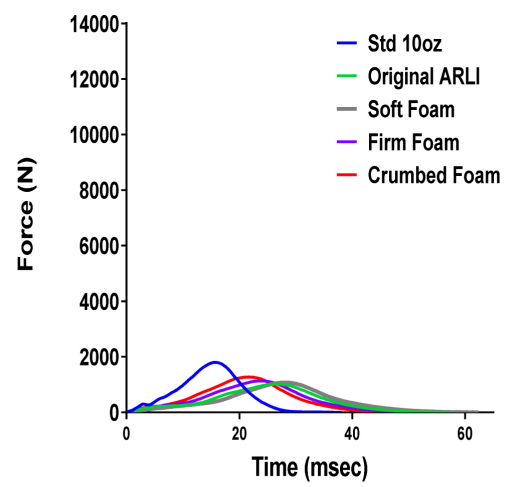

3 metres

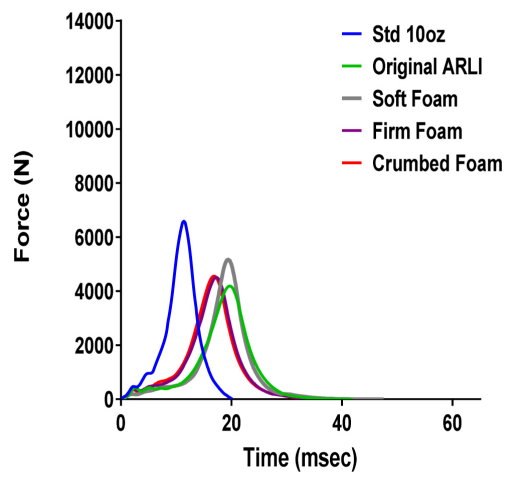

5 metres

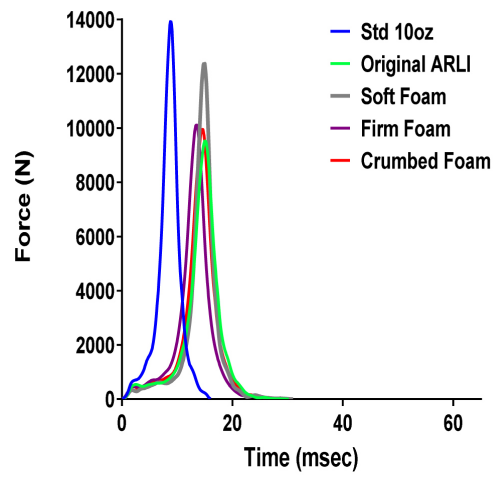

2 metres

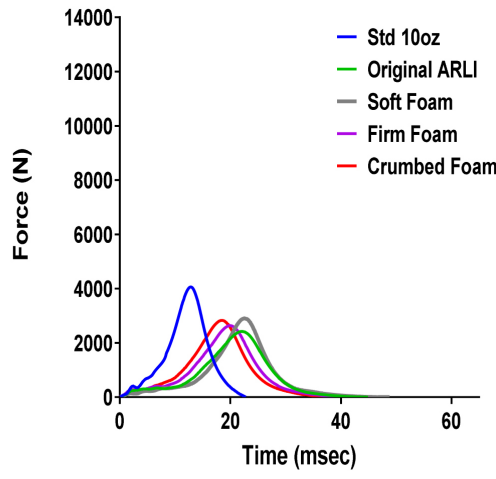

4 metres

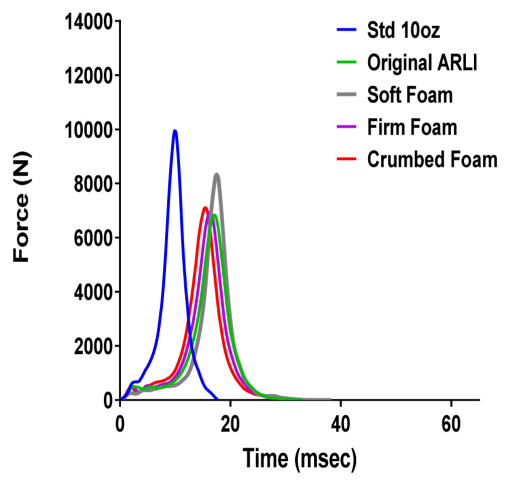

Figure 28. Force-time curves for different glove types and drop heights. Each curve relates to the trial producing the third highest peak impact force from a series of 10 drops.

protective than the Soft Foam glove when the air release hole pattern was controlled, it seems likely that the soft foam allowed too much air release during the initial glove deformation phase.

As can be discerned from the force-time curves, the peak rate of force development (maximum curve steepness) was less for the Original ARLI glove than 
for any of the other gloves. This is highlighted also in Figure 29. At a drop height of 1 metre, the mean peak rate of force development for the Soft Foam glove was similar to that of the other low-impact gloves, but at all other drop heights it yielded values considerably higher than them, presumably because the characteristics of the foam allowed relatively rapid compression. The means for the Original ARLI glove were $~ 58 \%, 68 \%, 61 \%, 51 \%$ and $49 \%$ less than those for the Std 10oz glove at drop heights of 1,2, 3, 4 and 5 metres respectively. For the Firm Foam and Crumbed Foam gloves, increases in the values as a function of drop height occurred almost in parallel with those for the Original ARLI glove, although the values were consistently a little higher.

In Figure 30, contact times between glove and force plate are presented. At each drop height, contact times for the four prototype low-impact gloves were inversely related to the firmness of foam in the bladder. The fact that the Soft

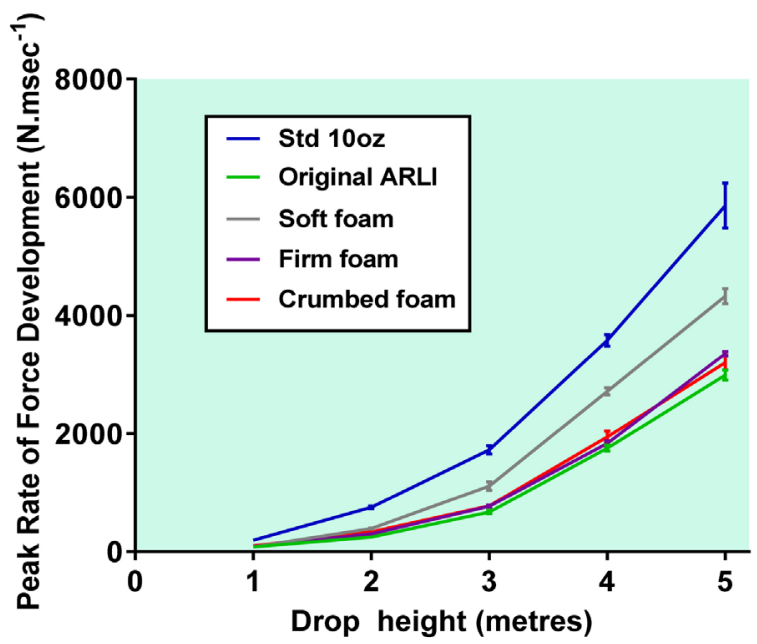

Figure 29. Peak rates of force development for various combinations of glove type and drop height. The curves are based on mean values for five drops that produced the highest five peak impact force readings out of 10 drops. The bars show the standard deviations for the five readings.

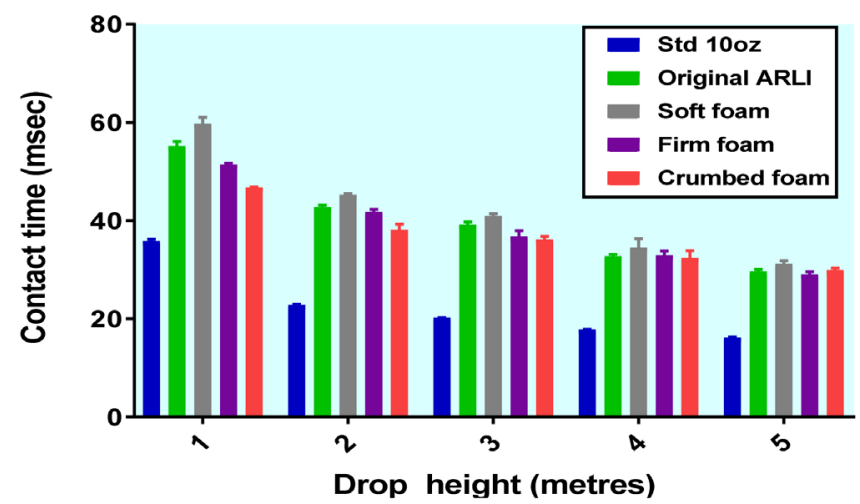

Figure 30. Contact times between glove and force plate for different glove types and drop heights. Each bar represents the mean of five glove drops that produced the highest peak forces within a series of 10 drops under the specified condition. Standard deviations of the five drops are also shown. 
Foam glove always had the longest contact times among the low-impact prototypes, but also produced the highest peak impact forces and peak rates of force development at drop heights of 3 metres and above, indicated that optimization of protective effect depends on more than just maximizing contact time. Use of glove materials that prevent maximum glove compressibility from being approached either too rapidly or too slowly is evidently also important. In our experiment, the performance of the Soft Foam glove appeared to be limited by the latter factor. On the other hand, the slightly diminished performance of the Firm and Crumbed Foam gloves relative to the Original ARLI glove may have been attributable to their shorter contact times, with the latter likely resulting from difference in the air opening arrangement, a small difference in foam firmness, or both.

Calculated areas under the force-time curves, calculated by the trapezoid method, are shown in Figure 31. Overall, the values for the Std 10oz, Original ARLI and Firm Foam gloves were quite similar. The most striking finding was that the Crumbed Foam and Soft Foam gloves, which had the lowest masses, tended to produce the highest values. The reasons for this are unclear, but it is possible that the lesser amount of material in these gloves reduced their capacity to store some of the impact energy.

In sum, the findings of the experiment led us to infer that a six-hole system for air ingress and air egress could be incorporated into our pneumatic gloves without substantially compromising protective performance relative to that obtained when a single larger air channel was employed. This was considered important in terms of the aesthetics of a glove product. The experiment also demonstrated a potential for negative consequences from any attempt to use overly soft foam to constitute a glove bladder skeleton intended to reduce the force of initial glove impact. Finally, it showed that when hole pattern and foam density were held constant, the use of crumbed foam to form the bladder skeleton offered no advantage over the use of a single, custom-shaped foam piece, meaning

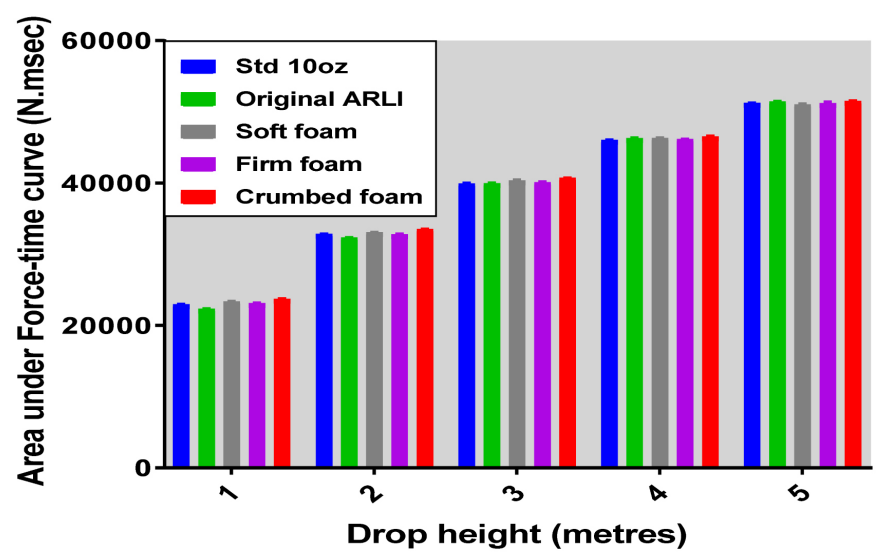

Figure 31. Calculated area under the force-time curve for various conditions of glove type and drop height. The columns indicate means for five glove drops that produced the highest peak force readings within a series of 10 drops. Standard deviations for those five drops are also shown but are so small as to be barely perceptible. 
that any effect of the crumbed foam in increasing the overall air content of the bladder was inconsequential.

\section{Another Field Trial}

In July 2016, a Sydney-based club that had been running a combined boxing and modified boxing (Box' Tag) program for more than a decade and had participated in previous testing and assessment of glove prototypes expressed interest in conducting a field test with the latest low-impact gloves. For this purpose, eight new pairs of ARLI gloves (four red and four blue) were manufactured and provided to the club. Over the following month the gloves, samples of which are shown in Figure 32, were used in a series of sparring sessions, particularly by junior athletes but also by others.

The Head Coach of the club provided us with written and verbal feedback during the trial and with additional verbal comments at its end. He indicated that the club members believed that the gloves looked smart and "worked really well" in terms of impact force reduction but perceived them as feeling "strange" and somewhat uncomfortable. There were specific complaints relating to a tendency for the gloves to rotate around the wrists during impacts and several athletes felt that the fist was too tightly constrained, with consequent inability to obtain even partial relief from the muscular effort required to maintain the fist in a fully clenched fist position. There were two reports of hand cramps after several rounds of sparring. Additionally, the Head Coach intimated that after using the prototype gloves during a couple of sparring sessions, the junior athletes began to request that they be allowed to return to "real gloves".

The major recommendation for improvement of the low-impact gloves was that they should have a separate thumb compartment, since this would both provide an anchor point to prevent glove rotation and decrease the volume of the hand needing to be contained in the main fist compartment. It was also suggested that the width of the gloves should be increased. An encouraging outcome of the exercise was advice from the club that it would be keen to take part in future glove trials.

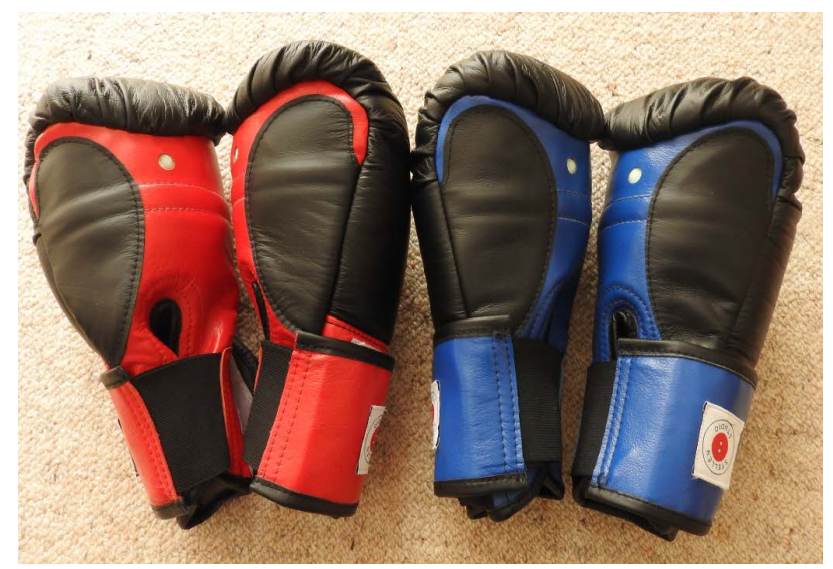

Figure 32. ARLI gloves of the type provided for the field trial in Sydney. 
Throughout the whole process of our development of low-impact glove prototypes, we had quite regularly heard the opinion that a separate thumb compartment was needed, but had resisted it because of statements from medical authorities concerning the potential merits of thumbless gloves as a means for reducing injuries [48] [49] and also because incorporation of a thumb compartment would increase the complexity and cost of glove production. In the aftermath of the Sydney trial, however, it became clear to us that a positive response to the feedback could be crucial to glove uptake.

\section{Production of a Prototype Glove with a Thumb Compartment}

In September 2016, our first prototype air-release glove with a thumb compartment was produced (see Figure 33). The location of the thumb compartment relative to the main section of the glove had to be a little different from that typical of conventional gloves, because of the different placement of the remainder of the hand within the glove. Several other new features were also introduced. A horizontal "bar" made of cloth was inserted into the main glove compartment to help guide the hand into the required closed fist position. Instead of leather, a breathable and more flexible webbed material was used to construct the front section of the glove. Combined with the removal of the thumb from the main glove compartment, this was designed to greatly reduce any feelings of constraint of the hand. It also removed the need to incorporate specific air passages into the front section of the glove, since air released from and returning to the glove bladder could easily pass through the webbed material. Visual resemblance to a conventional glove was therefore increased.

Over the following few weeks, we showed the new prototype glove to various members of the local boxing community, and produced some further prototypes embodying adjustments based on their comments and recommendations. The primary adjustments related to ensuring that the thumb could be held in a

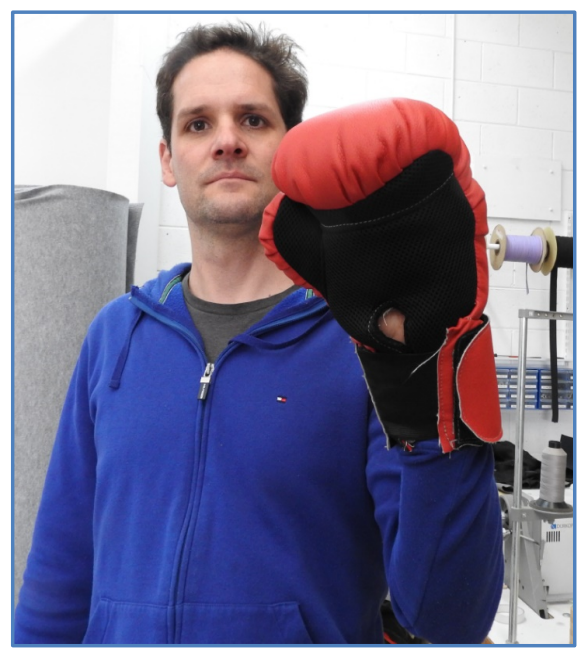

Figure 33. Our first prototype ARLI glove with a separate thumb compartment. 
comfortable, natural and safe position. As we progressed, we received majority feedback that the new glove was a substantial improvement on the previous version.

While the development of the new glove was occurring, we were advised that a consortium of organizations led by Boxing Australia Limited [the entity responsible for administration of amateur boxing in Australia] had obtained a grant to introduce a modified boxing program into a number of schools and other institutions in northern India. The grant included an allocation for manufacture of 60 pairs of low-impact gloves to support the program. We consulted with the Indian partners in the program as to whether thumbed or thumbless gloves should be provided and highlighted the arguments for both options. They expressed a strong preference for the gloves with thumb compartments, on the grounds that similitude to conventional gloves would be likely to facilitate acceptance.

Before initiating a small production run of the new gloves, we needed to ensure that they would be as effective as the prior air-release gloves in providing impact protection.

\section{Laboratory Testing of the Thumbed Glove}

Initial laboratory testing of the prototype ARLI glove with the separate thumb compartment was carried out at the University of Canberra in December 2016. The glove was compared with both a Std $10 \mathrm{oz}$ glove and a thumbless ARLI glove. Again, a drop testing protocol was employed, with each of the three glove types being dropped on to the force plate 10 times from heights of 1 to 5 metres, with the first drop height being 3 metres, followed by 2, 1, 4 and 5 metres. The thumbed ARLI glove was tested first, then the Std $10 \mathrm{oz}$ glove and finally the thumbless ARLI glove. The force plate was covered by a new mat consisting of EVA 75 material with a thickness of $25 \mathrm{~mm}$.

The peak impact forces recorded with the different glove types are shown in Figure 34 .

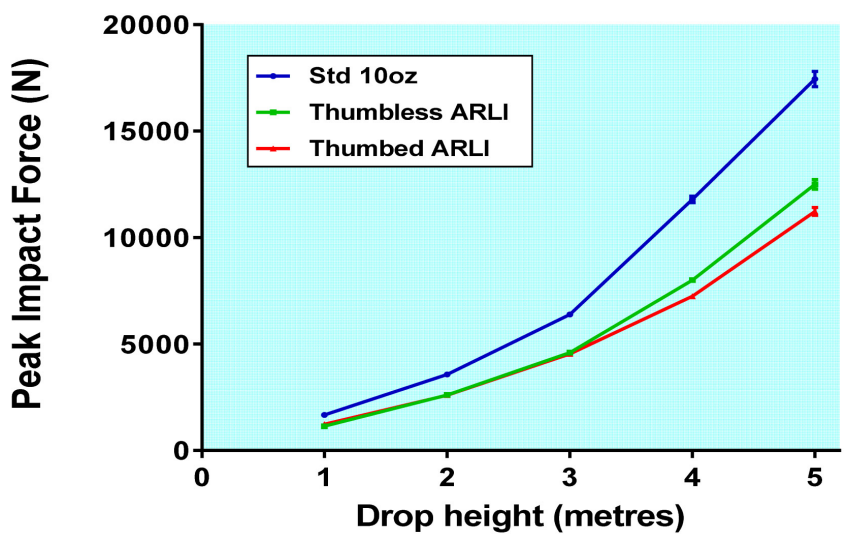

Figure 34. Relationship between peak impact force and drop height for a Std 10oz glove and thumbed and thumbless low-impact glove prototypes. Each data point on the graph represents the mean of the highest five values recorded from 10 glove drops. 
For both low-impact glove prototypes, the peak forces were much lower than those observed with the conventional glove. We calculated a geometric mean peak force for each glove type, an approach entailing inclusion of all readings at all drop heights while minimizing any tendency for readings obtained at the higher drop heights to bias the results. The geometric mean was $5846 \mathrm{~N}$ for the Std $10 \mathrm{oz}$ glove, $4123 \mathrm{~N}$ for the thumbless ARLI glove and $4008 \mathrm{~N}$ for the ARLI glove with the thumb compartment. Relative to the Std $10 \mathrm{oz}$ glove, the thumbless ARLI glove therefore reduced the geometric mean peak force by $\sim 29.5 \%$ while the thumbed glove reduced it by $\sim 31.5 \%$. We considered this small difference likely due to minor variations in bladder characteristics resulting from our manual construction of the bladders.

Qualitatively similar results were obtained in relation to peak rate of force development. Geometric mean values for all drops across all drop heights were 1606, 741 and $647 \mathrm{~N} \cdot \mathrm{msec}^{-1}$ for the Std 10oz, thumbless ARLI and thumbed ARLI gloves respectively. Compared to the Std $10 \mathrm{oz}$ glove, the reduction in peak rate of force development was $\sim 54 \%$ for the thumbless ARLI glove and $\sim 60 \%$ for the thumbed ARLI glove.

The above results reinforced our previous findings regarding the ability of ARLI gloves to substantially decrease peak impact forces and indicated that minor changes in glove structure required to include a thumb compartment did not compromise the protective effect. There were, however, some quantitative differences that merited consideration. At drop heights up to and including 3 metres, the peak forces for the thumbless ARLI glove were essentially unchanged from those measured for a glove of the same type six months earlier, but at drop heights of 4 and 5 metres, the peak forces were increased by $16 \%-25 \%$. In the case of the Std 10oz glove, the readings at drop heights of 1 - 3 metres were 2\% $12 \%$ below those measured six months earlier, whereas the readings at 4 and 5 metres were $17 \%-25 \%$ higher. Since the calculated area under the force-time curve was very similar for the two series of tests and certainly not higher for the second series (see Figure 35) it seems improbable that the changes were due to alteration of force plate calibration. Instead, the most plausible explanation for the higher peak force readings in December is our introduction of a new mat to cover the force plate.

Although the new mat ostensibly consisted of the same material as the old one, and was of the same thickness, batch variability associated with the production of such materials may have caused it to be slightly harder. With the gloves being softer than the target, the effect of target characteristics relative to glove characteristics on peak impact forces could be expected to increase with drop height. The fact that introduction of the new force plate covering was associated with higher peak force readings only at the highest drop heights therefore accords with the notion that the properties of that covering were probably responsible for the change.

The study served partly to highlight the importance of target characteristics in 


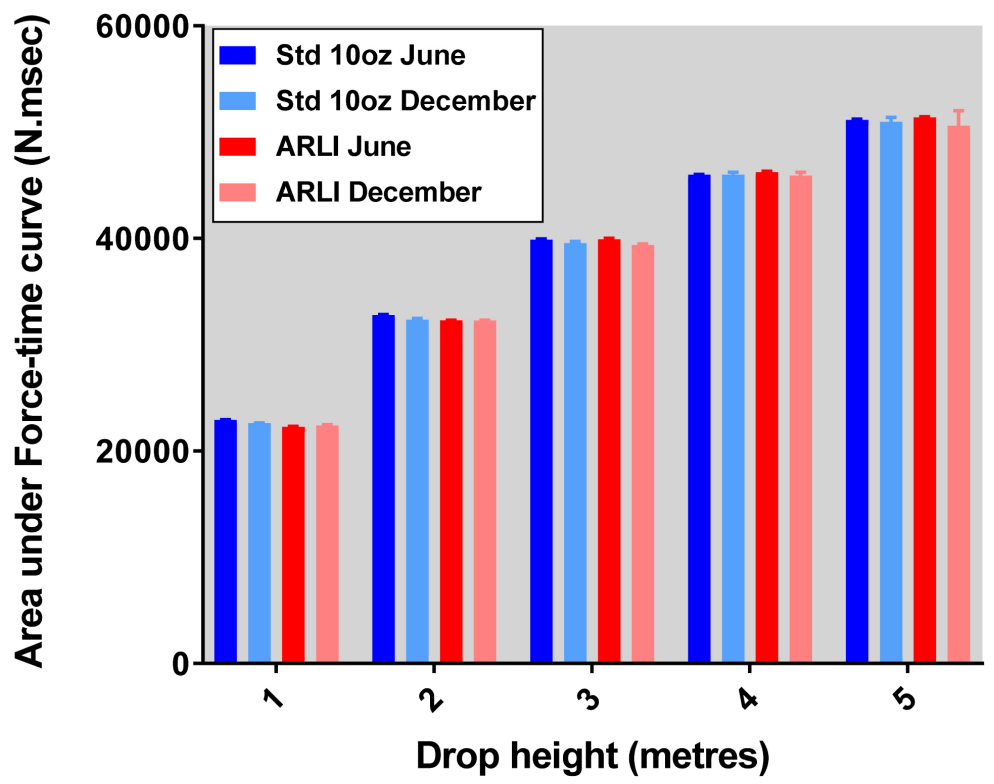

Figure 35. Calculated area under the force-time curve associated with dropping two types of gloves on to a force plate from heights of 1 - 5 metres in June and December 2016. The columns indicate means for five glove drops that produced the highest peak impact forces.

determining the peak impact forces generated by a given level of impact energy as well as the relativity of the peak forces produced by different glove types. There was, however, no change to our observation that ARLI gloves could markedly reduce peak forces across a range of impact energy levels.

Given that the ARLI glove with the separate thumb compartment was at least as effective as our prior prototype in decreasing peak impact forces and rates of force development, we decided to proceed with manufacture of multiple pairs to support the upcoming project in India.

\section{A Move to Larger-Scale Production}

To cater for the scheduled commencement date of the Indian project, the task of producing 60 pairs of the latest low-impact gloves had to be completed in less than a month. Meeting this requirement entailed overcoming some unforeseen challenges. Obtaining expeditious supply of some glove components proved problematic. Enkay (India) had provided bladders as samples to support our R \& $\mathrm{D}$ activities but was found to have a quite substantial minimum order quantity when larger numbers of the bladders were required. Since our budget did not permit purchase of the minimum order quantity, we had to pursue negotiations. These were eventually successful, but by then a fortnight had been lost. In addition, we under-estimated the time needed for construction of the gloves through a basic "assembly line" process that was implemented. Nevertheless, 30 pairs of gloves were produced by Stellen Studio and shipped to India before the end of 2016, and the same occurred again during the first three weeks of 2017 (see Figure 36). 


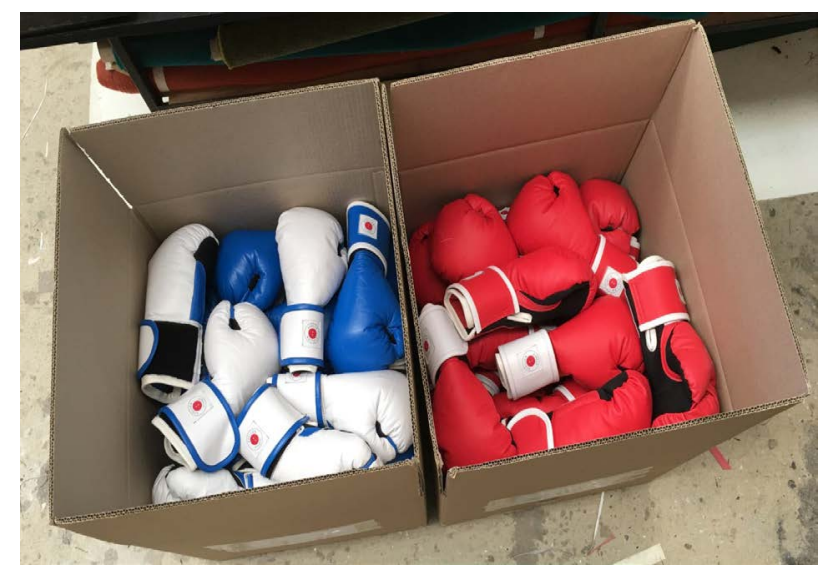

Figure 36. The first batch of 30 pairs of ARLI gloves ready for shipment to India.

\section{Initiation of Glove Production in India}

With a view to decreasing the costs of glove production and facilitating supply of low-impact gloves to organizations and individuals participating in the modified boxing program in India, we began investigating possibilities for Indian manufacture of the gloves. Contact was established with Paramount Enterprises, a company based in Dehradun, the capital city of the northern Indian state of Uttarakhand. The company was shown samples of the low-impact gloves and provided with a written and illustrated blueprint for their production. In February 2017, Paramount Enterprises produced its first prototype pair of the gloves and sent them to Australia for evaluation (Figure 37).

Three weeks later, the gloves were tested at the University of Canberra, with a representative of Paramount Enterprises in attendance. The Indian gloves were compared with a similar glove produced in Australia and a Std 10oz glove. The experimental protocol was essentially identical to that employed in our prior drop testing experiments, with each of the gloves being dropped on to the force plate 10 times from each of five heights. The initial drop height was 3 metres, followed successively by 2, 1, 4 and 5 metres. The Std $10 \mathrm{oz}$ glove was tested first, followed by the ARLI glove produced in Australia (Aust ARLI), the right-hand glove made in India (Ind ARLI Right), and then the left-hand glove made in India (Ind ARLI Left). The force plate was covered with the same $25 \mathrm{~mm}$ thick mat used in the last of the studies described above.

The mass of the Ind ARLI Right glove was $278 \mathrm{~g}$ while that of the Ind ARLI Left glove was $274 \mathrm{~g}$. Corresponding figures for the Aust ARLI and the Std 10oz gloves were $318 \mathrm{~g}$ and $265 \mathrm{~g}$ respectively. The slightly lower mass of the Indian-made gloves relative to the Aust ARLI glove reflected an intention to produce them in a smaller size to allow for the fact that the modified boxing program in India was targeted primarily at $12-16$ year-old school students rather than adults.

The peak force readings obtained in the experiment are summarised in Figure 38. For all drop heights, the readings for the three ARLI gloves were well below 


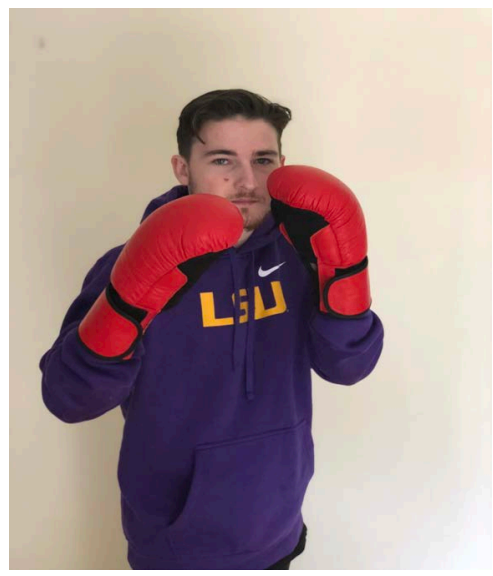

Figure 37. Receipt in Australia of the first pair of ARLI gloves made in India.

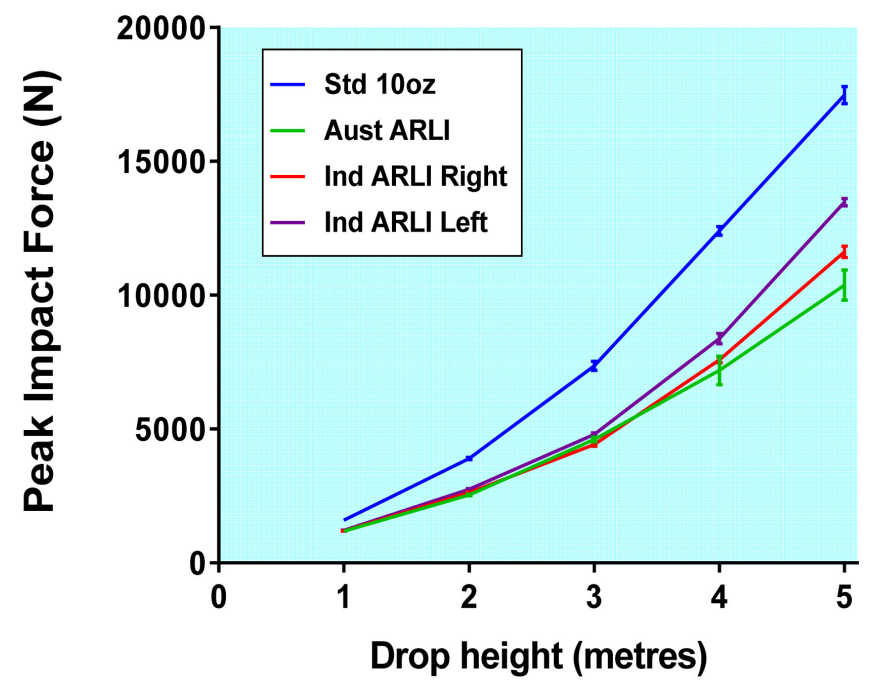

Figure 38. Peak impact forces for a conventional 10oz glove (Std 10oz) and ARLI gloves produced in Australia (Aust ARLI) and India (Ind ARLI Right and Ind ARLI Left). The curves reflect mean values of the highest five readings recorded from 10 drops. Standard deviations of the five readings are also shown.

those for the Std 10oz glove. At drop heights of 1 - 3 metres, the peak forces for the Aust ARLI glove and the Ind ARLI Right glove were quite similar, but the Aust ARLI glove gave slightly greater protection at drop heights of 4 and 5 metres. The peak forces measured with the Ind ARLI Left glove were always a little higher than those recorded with the other ARLI gloves.

The geometric mean peak force, calculated from all drops across all drop heights, was $6135 \mathrm{~N}$ for the Std $10 \mathrm{oz}$ glove, $3884 \mathrm{~N}$ for the Aust ARLI glove, $4057 \mathrm{~N}$ for the Ind ARLI Right glove and $4408 \mathrm{~N}$ for the Ind ARLI Left glove. Thus, relative to the Std $10 \mathrm{oz}$ glove, the Aust ARLI glove reduced the overall geometric mean peak force by $\sim 37 \%$ and the Ind ARLI Right glove reduced it by $\sim 34 \%$. While the Ind ARLI Left glove was less effective, the overall geometric mean peak force that it produced was still $\sim 31 \%$ less than that recorded with the Std $10 \mathrm{oz}$ glove. 
For peak rate of force development, the geometric means were 1599, 628, 675 and $799 \mathrm{~N} \cdot \mathrm{msec}^{-1}$ for the Std $10 \mathrm{oz}$, Aust ARLI, Ind ARLI Right and Ind ARLI Left gloves respectively. Compared to the Std 10 oz glove, the Aust ARLI glove therefore decreased the peak rate of force development by $\sim 61 \%$, while the Ind ARLI Right glove decreased it by $\sim 58 \%$ and the Ind ARLI Left glove by $\sim 50 \%$.

Force plate contact times for the Aust ARLI glove tended to be longer than those for the Ind ARLI Right glove, while the times for the latter were slightly longer than those for the Ind ARLI Left glove (except at a drop height of 5 metres). Contact times for the Std $10 \mathrm{oz}$ glove were consistently much shorter than for any of the prototype ARLI gloves (Figure 39).

We plotted the relationship between contact time and peak force for the different gloves and fitted power series regression curves to the data (see Figure 40). The plot showed that for any given contact time, peak force was lowest for the Std $10 \mathrm{oz}$ glove, intermediate for the gloves produced in India, and highest for the Aust ARLI glove. This indicates that if a given level of impact energy was applied to a target over a specific time period, the Std $10 \mathrm{oz}$ glove would be the most effective shield in terms of minimizing the peak impact force. A major advantage of the ARLI gloves appears to be their ability to act more as springs than as shields, with the spring-like attributes prolonging contact times. Provided that the spring-like attributes are appropriately "tuned" to deal with the magnitude of impact energy encountered, the increased contact time allows the energy to be distributed over a longer period and this can outweigh the lesser shield-like traits and enable peak force reduction considerably exceeding that achievable with a conventional glove. Optimizing the capacity and time course of air release and

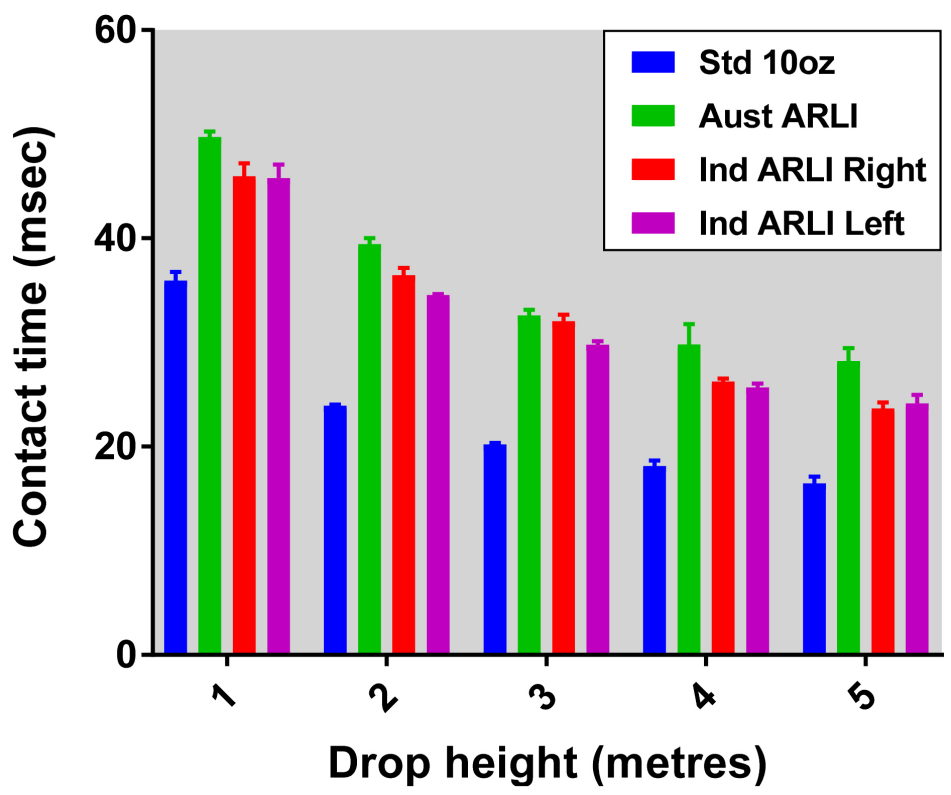

Figure 39. Effect of drop height on force plate contact times for a conventional $10 \mathrm{oz}$ glove and air-release gloves manufactured in Australia and India. The values shown are means for five glove drops that produced the highest peak force readings within a series of 10 drops. Standard deviations for the five drops are also shown. 


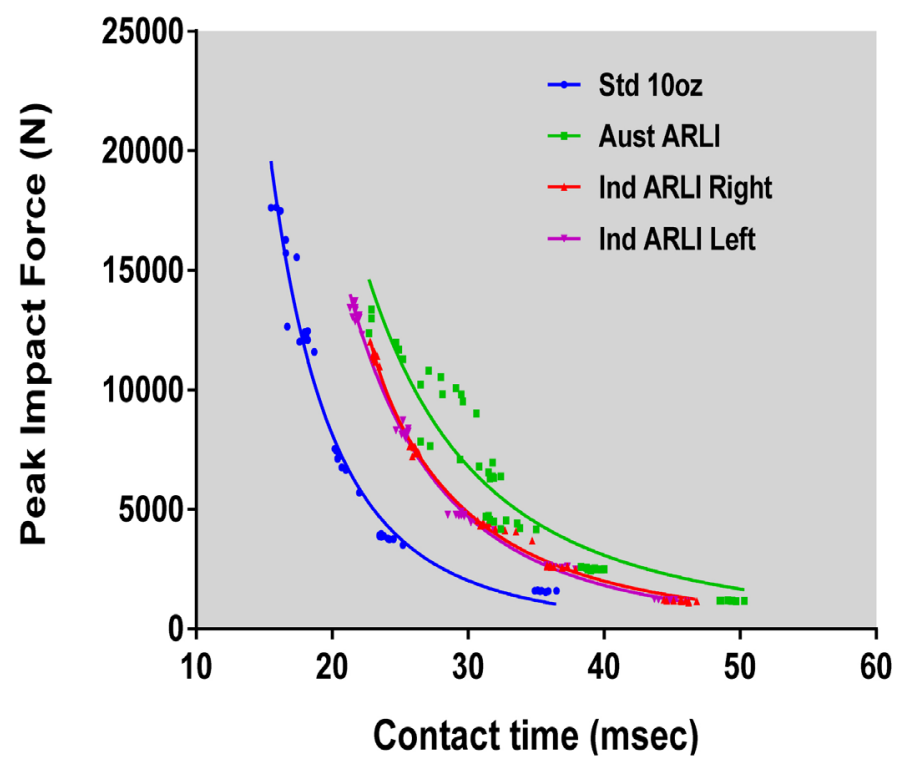

Figure 40. Relationship of peak impact force to contact time for each glove type with calculated power series trend lines shown.

return is crucial to the tuning of the spring characteristics of the air-release gloves.

In Figure 40, the regression curves for the right- and left-hand Indian gloves are essentially identical. We saw this as implying that they had the same material qualities, and that the superior protective effect of the right-hand glove stemmed from better spring tuning (probably relating to the size and/or positioning of the holes in the glove bladder) that enabled slightly longer glove-target contact times.

The most important outcome of the above experiment, though, was demonstration of the viability of manufacture of highly functional ARLI gloves by an independent company.

\section{Further Feedback on the Gloves}

We subsequently showed the latest prototype gloves to an internationally renowned boxing coach who has more than 40 years of experience in the sport. After trying them on, he opined that their acceptance by serious boxers remains very unlikely, but did suggest that they could have applications during early learning of boxing skills. The gloves were also shown to the Head Coach of the Sydney club that has run a combined boxing and modified boxing program for many years and has been the site of some of our glove trials. He too put on the gloves (see Figure 41) and commented that they are now visually attractive, comfortable to wear, and highly suitable for use in the modified boxing context.

In May 2017, an Indian colleague who is playing a primary role in implementing and administering the modified boxing program there provided the following written feedback:

"The gloves are being taken very well by the trainees. In fact, it is a matter of 


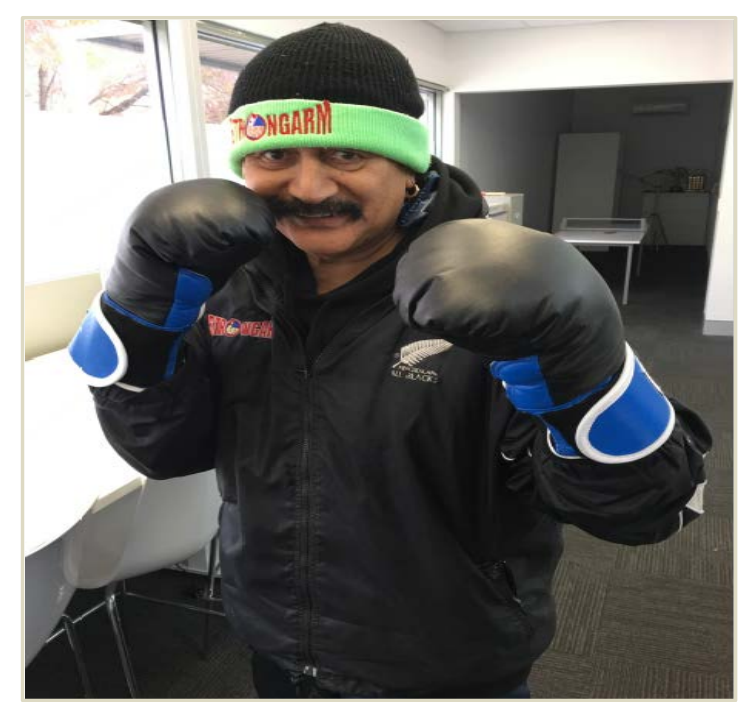

Figure 41. Head Coach of Sydney club with long history of modified boxing wearing latest ARLI gloves.

pride for them to be able to wear them. Many of them get a chance at it only once a week as the number of gloves given to each school is limited. We have ten schools... Given the availability of only sixty pairs among them, the gloves have taken on an air of exclusivity, which I feel may be also a good thing sometimes, because trainees try harder to perform so that then they get a chance to wear them".

\section{More Recent Progress}

In October 2017 Paramount Enterprises in India produced 60 pairs of ARLI gloves to add to the 60 Australian-manufactured pairs already being used in the modified boxing program there. These new gloves have been well-received. ARLI gloves were used in a public performance of modified boxing held in Dehradun towards the end of 2017 (Figure 42).

Based on initial success of the modified boxing program in India, Boxing Australia was able to obtain further funding that now guarantees continuation of the program until the end of September 2018. Encouraged by these developments, Boxing Australia is now seeking to expand modified boxing activities in its domestic domain. In April 2018, it contracted Paramount Enterprises to produce 60 pairs of ARLI gloves for export to Australia to cater for this initiative and the consignment has now been delivered. Stellen Studio continues to manufacture ARLI gloves in small batches each incorporating minor alterations as part of ongoing research efforts aimed at gradual glove improvement. It is envisaged that this will enable regular updating of blueprints provided to Paramount Enterprises for larger scale production.

\section{Reflection}

We have carried out a 5-year design process that has led to the creation of 


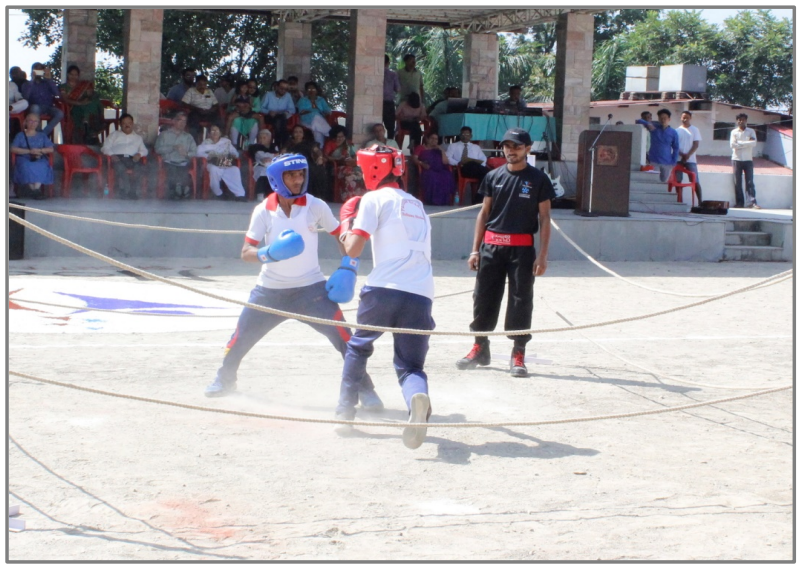

Figure 42. Use of ARLI gloves during a public performance of modified boxing in India. In this performance, impacts to the head and neck were prohibited and participants worked together to put on an entertaining display of fitness and skill rather than striving for individual victory. Photograph kindly provided by Sumit Kumar Agarwal of Tanjun Associate, India.

pneumatic boxing gloves that substantially reduce impact forces delivered to an opponent and are now acceptable to at least a niche community engaged in a modified form of boxing that emphasises participant safety. The design process has entailed a need for repeated problem conception, identification of possible solutions that could be achieved within project constraints, consultation with interested parties including several with advanced technical expertise, creation of models and prototypes, and testing of the prototypes in both field and laboratory situations. Evolution of the gloves has been non-linear and has required adoption of directions and techniques that we did not foresee at the outset. To some degree, it has been based on opportunism made possible by initially unplanned access to facilities and partner expertise.

In their present embodiment, the gloves are almost certainly not perfect, but to use a term introduced by Simon [37], they have reached a point of being contextually "satisficing" (i.e. satisfactory and sufficient to fulfil a particular purpose for a particular group). Many aspects of them remain amenable to adjustment. Such adjustment is likely to be necessary to maintain acceptance by existing users and to stimulate wider uptake, but even in their current form, the gloves represent an accumulation of knowledge through design methods.

Available literature shows that boxers can sometimes deliver peak impact forces of more than $5000 \mathrm{~N}$ to targets in laboratory and field situations [60] [61] [62], and in one study, a hooked punch to the head of a crash test manikin generated a peak impact force of $\sim 8000 \mathrm{~N}$ [47]. Research in which force transducers were located in the gloves of professional boxers demonstrated that while most impacts recorded during actual bouts produced peak forces of less than $2000 \mathrm{~N}$ readings above $5000 \mathrm{~N}$ could be encountered [62]. Based on these findings and allowance of some tolerance to cater for the possibility that forces exceeding those observed in research settings might occasionally occur in field environ- 
ments, gloves aimed at damping peak impact forces probably need to be effective across a range of standard glove equivalent peak forces extending from below $2000 \mathrm{~N}$ to at least 10,000 N. Our current ARLI gloves meet this criterion and, when employed in conjunction with other safety measures, could be expected to reduce the risk and/or severity of boxing injuries [57].

\section{Acknowledgements}

The work described above was supported by grants from the Australian Olympic Committee (through the Olympic Solidarity Program) and the Queensland Academy of Sport. The authors wish to strongly acknowledge the large contribution made by the staff and members of the Canberra Police Community Youth Club to the field testing of glove prototypes, and assistance in that regard also from the Strongarm Boxing \& Fitness Club in Sydney. Luke and Katie Eldridge contributed greatly to the project through design and manufacture of the mechanical fist used in many of our experiments. Anthony Ashmore of AJA Engineering, Bill Shelly of the University of Canberra and Jamie Plowman and Michael Steinebronn of the Australian Institute of Sport all provided valuable technical support. Associate Professor Stephen Trathen of the University of Canberra assisted with aspects of industrial design and Dr. Richard Helmer of Superinteractive Pty Ltd. provided engineering counsel. Dr. Chris Barnes of the University of Canberra often assisted with data collection. Dan Benham of HART Sport showed consistent interest in our work and supported us in multiple ways. Enkay (India) aided us by waiving minimum order requirements for bladders needed for prototype glove construction. Professor Mike Xie and Dr. Jianhu (Chris) Shen of RMIT University, Melbourne, gave helpful advice in the early stages of the project. They also participated in laboratory testing of our first low-impact glove prototype, as did Sydney inventor Greg Hay. Manufacture of prototype low-impact gloves in India was coordinated by Jalaj Anand of Paramount Enterprises, who also took part in testing of the first of those gloves in Canberra. Sumit Kumar Agarwal of Tanjun Associate and Rekha Dey of SEDA (India) provided important feedback on utility of prototype gloves in the Indian context.

\section{References}

[1] International Boxing Association. Boxing: A Universal Sport [Internet]. International Boxing Association National Federations. https://www.aiba.org/national-federations/

[2] Perkins, P., Hahn, A., Lucas, R. and Keegan, R. (2014) The Boxing Conundrum: Is There a Place for a New Variant of the Sport? Journal of Research in Humanities and Social Science, 2, 9-25.

[3] Smillie, M. (2003) There Is No Sport Like Boxing. British Columbia Medical Journal, 45, 473-474.

[4] Hardy, J. (2013) The Ignoble Art. NewScientist, 219, 26-27. https://doi.org/10.1016/S0262-4079(13)61991-0 
[5] Svinth, J. (2007) Death under the Spotlight: Analyzing the Data. Journal of Combative Sport, 2007, 1-19.

[6] Roberts, G.W., Allsop, D. and Bruton, C. (1990) The Occult Aftermath of Boxing. Journal of Neurology, Neurosurgery \& Psychiatry, 53, 373-378. https://doi.org/10.1136/jnnp.53.5.373

[7] Lundberg, G. (1993) Medical Arguments for Nonparticipation in Boxing. In: Medical Aspects of Boxing, CRC Press, Florida USA, 11-15.

[8] Unterharnscheidt, F. (1995) A Neurologist's Reflections on Boxing. V. Conclude Remarks. Revista de Neurologia, 23, 1027-1032.

[9] Zhang, L., Heier, L.A., Zimmerman, R.D., Jordan, B. and Ulug, A.M. (2006) Diffusion Anisotropy Changes in the Brains of Professional Boxers. American Journal of Neuroradiology, 27, 2000-2004.

[10] Pineda, P. and Gould, D. (2010) The Neuroanatomical Relationship of Dementia Pugilistica and Alzheimer's Disease. Neuroanatomy, 9, 5-7.

[11] Cabanis, E.-A., Iba-Zizen, M.-T., Perez, G., Senegas, X., Furgoni, J., Pineau, J.-C., et al. (2010) Boxing: Traumatology and Prevention. Bulletin de l'Académie nationale de médecine, 194, 1219-1236.

[12] Bailey, D.M., Jones, D.W., Sinnott, A., Brugniaux, J.V., New, K.J., Hodson, D., et al. (2013) Impaired Cerebral Haemodynamic Function Associated with Chronic Traumatic Brain Injury in Professional Boxers. Clinical Science, 124, 177-189. https://doi.org/10.1042/CS20120259

[13] Neselius, S., Zetterberg, H., Blennow, K., Marcusson, J. and Brisby, H. (2013) Increased CSF Levels of Phosphorylated Neurofilament Heavy Protein Following Bout in Amateur Boxers. PLoS ONE, 8, e81249. https://doi.org/10.1371/journal.pone.0081249

[14] Tanriverdi, F., De Bellis, A., Battaglia, M., Bellastella, G., Bizzarro, A., Sinisi, A.A., et al. (2010) Investigation of Antihypothalamus and Antipituitary Antibodies in Amateur Boxers: Is Chronic Repetitive Head Trauma-Induced Pituitary Dysfunction Associated with Autoimmunity? Eur J Endocrinol, 162, 861-867. https://doi.org/10.1530/EJE-09-1024

[15] Kaste, M., Vilkki, J., Sainio, K., Kuurne, T., Katevuo, K. and Meurala, H. (1982) Is Chronic Brain Damage in Boxing a Hazard of the Past? The Lancet, 320, 1186-1188. https://doi.org/10.1016/S0140-6736(82)91203-X

[16] Casson, I.R., Siegel, O., Sham, R., Campbell, E.A., Tarlau, M. and DiDomenico, A. (1984) Does Swedish Amateur Boxing Lead to Chronic Brain Damage? 3. A Retrospective Clinical Neurophysiological Study. JAMA, 251, 2663-2667.

[17] McLatchie, G., Brooks, N., Galbraith, S., Hutchison, J.S.F., Wilson, L., Melville, I., et al. (1987) Clinical Neurological Examination, Neuropsychology, Electroencephalography and Computed Tomographic Head Scanning in Active Amateur Boxers. Journal of Neurology, Neurosurgery \& Psychiatry, 50, 96-99.

https://doi.org/10.1136/jnnp.50.1.96

[18] Haglund, Y. and Perrson, H.E. (1990) Does Swedish Amateur Boxing Lead to Chronic Brain Damage? 3. A Retrospective Clinical Neurophysiological Study. Acta Neurologica Scandinavica, 82, 353-360. https://doi.org/10.1111/j.1600-0404.1990.tb03316.x

[19] Oelman, B.J., Rose, C.M.E. and Arlow, K.J. (1983) Boxing Injuries in the Army. Journal of the Royal Army Medical Corps, 129, 32-37.

https://doi.org/10.1136/jramc-129-01-10 
[20] Potter, M.R., Snyder, A.J. and Smith, G.A. (2011) Boxing Injuries Presenting to U.S. Emergency Departments, 1990-2008. American Journal of Preventive Medicine, 40, 462-467. https://doi.org/10.1016/j.amepre.2010.12.018

[21] Beran, R. and Beran, J. (2009) The Law(s) of the Rings: Boxing and the Law. Journal of Law and Medicine, 16, 684-695.

[22] Brayne, H., Sargeant, L. and Brayne, C. (1998) Could Boxing Be Banned? A Legal and Epidemiological Perspective. BMJ, 316, 1813-1815.

https://doi.org/10.1136/bmj.316.7147.1813

[23] Anderson, J. (2007) The Legality of Boxing: A Punch Drunk Love. Journal of Law and Society, 34, 648-649. https://doi.org/10.1111/j.1467-6478.2007.00408_2.x

[24] Pagelow, M.D. and Pagelow, L.W. (1984) Alternative Views on Family Violence. In: Family Violence, Praeger Publications, New York, USA.

https://books.google.com.au/books?hl=en\&lr=\&id=VPPapvrJsTcC\&oi=fnd\&pg=PR $3 \& \mathrm{dq}=$ Pagelow + Pagelow + Alternative + views $+\mathrm{on}+$ family + violence\&ots $=\mathrm{d} 3 \mathrm{c} 4 \mathrm{lL} 1 \mathrm{kX}$ K\&sig=YkAoFif61K2JRighSsObweLw2ao

[25] Sugden, J. (1996) Boxing and Society. In: Boxing and Society, Manchester University Press, Manchester UK, 172-196.

[26] Baglio, S. (2000) The Muhammad Ali Boxing Reform Act: The First Jab at Establishing Credibility in Professional Boxing. Fordham Law Review, 68, 2257-2298.

[27] Pearn, J.H. (2000) Boxing, Brains and Balls. Medicine Today, 1, 146-148.

[28] American Medical Association (1999) Boxing Injuries.

[29] Stinson, S. (2012) Boxing Welcomes All the Health Risks. National Post. http://nationalpost.com/sports/boxing-welcomes-all-the-health-risks

[30] Perkins, P., Jamieson, A., Spratford, W. and Hahn, A. (2018) Evaluation of Ability of Two Different Pneumatic Boxing Gloves to Reduce Delivered Impact Forces and Improve Safety. World Journal of Engineering and Technology, 6, 457-491.

[31] Hahn, A.G., Helmer, R.J., Mackintosh, C., Staynes, L.M. and Blanchonette, I. (2011) Technological Foundations and Current Status of a Modified, Low-Risk Form of Competitive Boxing (Box’Tag ${ }^{\bowtie}$ ). Sports Technology, 4, 178-184. https://doi.org/10.1080/19346182.2012.725413

[32] Light-Contact Boxing. http://www.light-contact.ch/4-1-Light-Contact-Boxing.html

[33] Perkins, P., Hahn, A., Keegan, R. and Collis, I. (2014) Why Do Community-Based Athletes Choose to Participate in a Modified, Low-Risk form of Boxing? An Interpretative Phenomenological Analysis. Journal of Research in Humanities and Social Science, 2, 60-69. https://doi.org/10.9790/9467-2116069

[34] Wieringa, R. (2010) Design Science Methodology: Principles and Practice. Proceedings of the 32nd ACM/IEEE International Conference on Software Engineering, Cape Town, 1-8 May 2010, 493-494. https://doi.org/10.1145/1810295.1810446

[35] Cross, N. (1990) The Nature and Nurture of Design Ability. Design Studies, 11, 127-140. https://doi.org/10.1016/0142-694X(90)90002-T

[36] Dorst, K. (2011) The Core of "Design Thinking" and Its Application. Design Studies, 32, 521-532. https://doi.org/10.1016/j.destud.2011.07.006

[37] Simon, H.A. (1969) The Sciences of the Artificial. 1st Edition, MIT Press, Cambridge, Massachusetts.

[38] Ball, L.J., Maskill, L. and Ormerod, T.C. (1998) Satisficing in Engineering Design: Causes, Consequences and Implications for Design Support. Automation in Con- 
struction, 7, 213-227. https://doi.org/10.1016/S0926-5805(97)00055-1

[39] Hillier, B., Musgrove, J. and O’Sullivan, P. (1984) Knowledge and Design. In: Developments in Design Methodology, Wiley, New York, USA, 29.3.1-29.3.14.

http://citeseerx.ist.psu.edu/viewdoc/download?doi=10.1.1.468.9559\&rep=rep1\&type $=\mathrm{pdf}$

[40] Cross, N. (1993) Science and Design Methodology: A Review. Research in Engineering Design, 5, 63-69. https://doi.org/10.1007/BF02032575

[41] Hatchuel, A. (2001) Towards Design Theory and Expandable Rationality: The Unfinished Program of Herbert Simon. Journal of Management and Governance, 5, 260-273. https://doi.org/10.1023/A:1014044305704

[42] Mahdjoubi, D. (2009) Four Types of R \& D. Stavangaer, Norway. https://www.uis.no/getfile.php/1336726/Forskning/Senter\%20for\%20Innovasjonsfo rskning/Presentation\%20Four\%20Types\%20of\%20R\%26D\%20Darius.pdf

[43] Saffer, D. (2010) The Design Process and the Scientific Method. Kicker Studio. http://www.kickerstudio.com/2010/04/the-design-process-and-the-scientific-metho d/

[44] Mahdjoubi, D. (2003) Epistemology of Design. Integr Des Process Technol., 1-5.

[45] Lofgren, L. (1957) A Description of the New Pneumatic Boxing Glove. Medicine Sport, 11, 449-454.

[46] Carrillo, H. (2006) Pneumatic Device for Boxing Gloves to Reduce Head Trauma. Guaynabo, Puerto Rico, US 7043763 B2. https://www.google.com/patents/US7043763

[47] Mack, J., Stojsih, S., Sherman, D., Dau, N. and Bir, C. (2010) Amateur Boxing Biomechanics and Punch Force. Marquette, MI.

[48] Morrison, R.G. (1986) Medical and Public Health Aspects of Boxing. JAMA, 255, 2475-2480. https://doi.org/10.1001/jama.1986.03370180101041

[49] Wedrich, A., Velikay, M., Binder, S., Radax, U., Stolba, U. and Datlinger, P. (1993) Ocular Findings in Asymptomatic Amateur Boxers. Retina, 13, 114-119. https://doi.org/10.1097/00006982-199313020-00004

[50] Perkins, P., Helmer, R.J.N., Mackintosh, C. and Hahn, A.G. (2017) Reflections on Long-Term Development and Use of Automated Scoring Technology in a Sport (Modified Boxing) Context. World Journal of Engineering and Technology, 5, 455-480. https://doi.org/10.4236/wjet.2017.53040

[51] Sconiers, H.E. (2017) What Are the Rules for the Ounce Sizes of Boxing Gloves?. Livestrong.com.

https://www.livestrong.com/article/499018-what-are-the-rules-for-the-ounce-sizesof-boxing-gloves/

[52] NJ (2010) What Boxing Gloves to Use? ExpertBoxing.com.

https://www.expertboxing.com/boxing-basics/boxing-equipment/what-boxing-glov es-to-use

[53] Aurin, R. (2017) What Are the Benefits of Kangaroo Leather? Our Everyday Life. https://oureverydaylife.com/what-are-the-benefits-of-kangaroo-leather-12337468.ht $\underline{\mathrm{ml}}$

[54] KIAA. Leather. Kangaroo Industry Association of Australia.

[55] Wikipedia (2017) Wikipedia: Kangaroo Leather. https://en.wikipedia.org/wiki/Kangaroo_leather

[56] Waliliko, T.J., Viano, D.C. and Bir, C.A. (2005) Biomechanics of the Head for 
Olympic Boxer Punches to the Face. British Journal of Sports Medicine, 39, 710-719. https://doi.org/10.1136/bjsm.2004.014126

[57] Perkins, P., Jamieson, A., Spratford, W. and Hahn, A. (2018) Evaluation of Ability of Two Different Pneumatic Boxing Gloves to Reduce Delivered Impact Forces and Improve Safety. World Journal of Engineering and Technology, 6, 457-491. https://doi.org/10.4236/wjet.2018.62028

[58] Muthu, J.E.R.P. (2007) Mechanics of Silicon Micro Needle Penetration in Human Cadaver Skin and Skin Substrates, Master of Science, Lehigh, Pennsylvania, USA. https://preserve.lehigh.edu/cgi/viewcontent.cgi?article=1972\&context=etd

[59] Periyasamy, R., Anand, S. and Ammini, A.C. (2012) Investigation of Shore Meter in Assessing Foot Sole Hardness in Patients with Diabetes Mellitus: A Pilot Study. International Journal of Diabetes in Developing Countries, 32, 169-175. https://doi.org/10.1007/s13410-012-0085-Z

[60] Atha, J., Yeadon, M.R., Sandover, J. and Parsons, K.C. (1985) The Damaging Punch. Br Med J., 291, 1756-1757. https://doi.org/10.1136/bmj.291.6511.1756

[61] Smith, M.S., Dyson, R.J., Hale, T. and Janaway, L. (2000) Development of a Boxing Dynamometer and Its Punch Force Discrimination Efficacy. Journal of Sports Sciences, 18, 445-450. https://doi.org/10.1080/02640410050074377

[62] Pierce, J.D., Reinbold, K.A., Lyngard, B.C., Goldman, R.J. and Pastore, C.M. (2006) Direct Measurement of Punch Force during Six Professional Boxing Matches. Journal of Quantitative Analysis in Sports, 2, 1-17.

https://doi.org/10.2202/1559-0410.1004 